Document downloaded from:

http://hdl.handle.net/10251/82282

This paper must be cited as:

Molina Moreno, F.; García-Segura, T.; Martí Albiñana, JV.; Yepes, V. (2017). Optimization of buttressed earth-retaining walls using hybrid harmony search algorithms. Engineering Structures. 134:205-216. doi:10.1016/j.engstruct.2016.12.042.

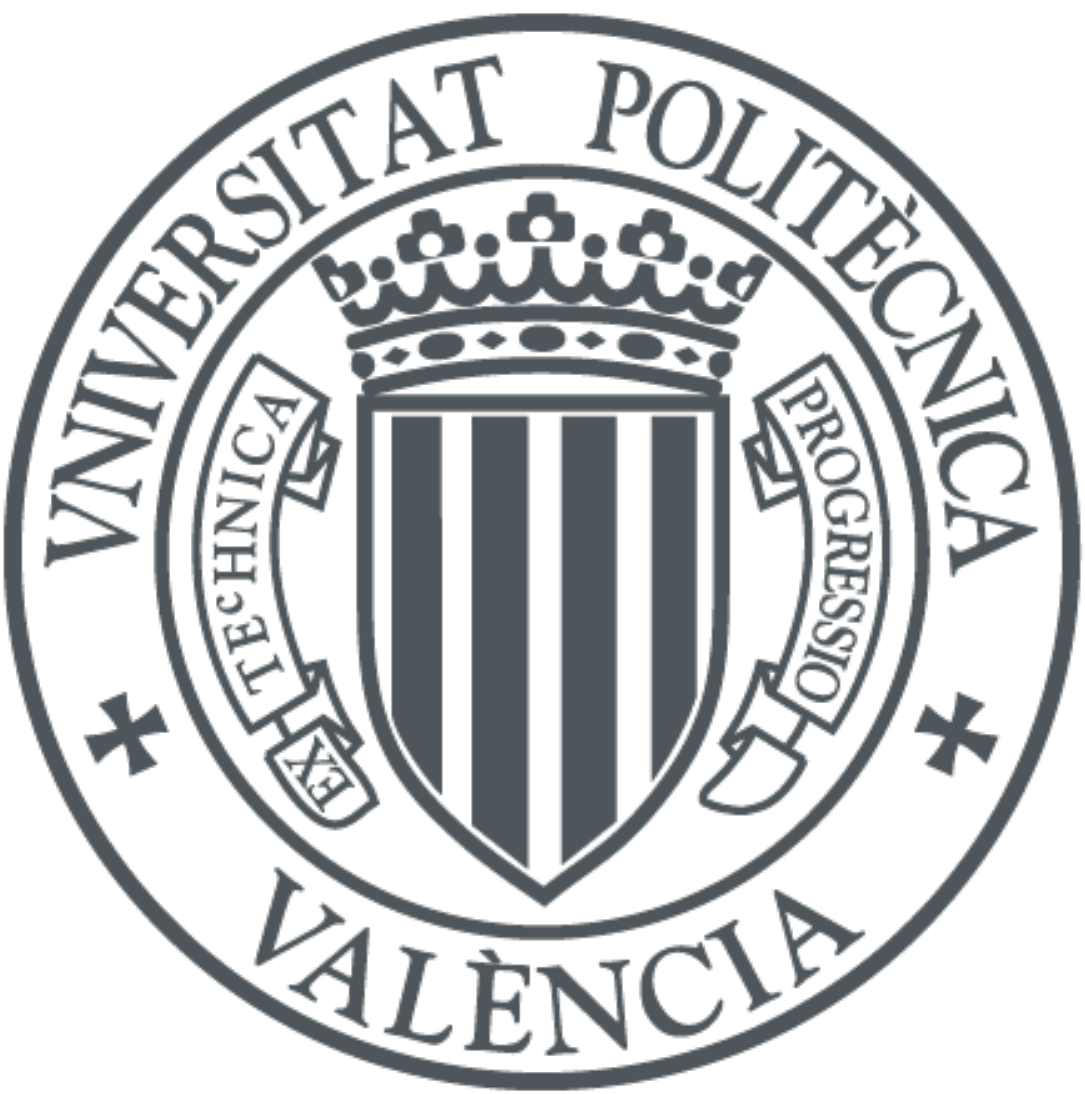

The final publication is available at

https://doi.org/10.1016/j.engstruct.2016.12.042

Copyright Elsevier

Additional Information 


\title{
Optimization of Buttressed Earth-Retaining Walls using Hybrid Harmony Search
}

\author{
Algorithms \\ Francisca Molina-Moreno $^{1}$ \\ Tatiana García-Segura ${ }^{2}$ \\ José V. Martî3 \\ Víctor Yepes ${ }^{4}$
}

\begin{abstract}
This paper represents an economic optimization of buttressed earth-retaining walls. We explore the optimum solutions using a harmony search with an intensification stage through threshold accepting. The calibration of the resulting algorithm has been obtained as a result of several test runs for different parameters. A design parametric study was computed to walls in series from 4-16 $\mathrm{m}$ total height. The results showed different ratios of reinforcement per volume of concrete for three types of ground fill. Our main findings confirmed that the most sensitive variable for optimum walls is the wall-friction angle. The preference for wall-fill friction angles different to $0^{\circ}$ in project design is confirmed. The type of fill is stated as the main key factor affecting the cost of optimum walls. The design parametric study shows that the soil foundation bearing capacity substantially affects costs, mainly in coarse granular fills $\left(F_{1}\right)$. In that sense, cost-optimum walls are less sensitive to the bearing capacity in mixed soils $\left(F_{2}\right)$ and fine soils of low plasticity $\left(F_{3}\right)$. Our results also showed that safety against sliding is a more influential factor for optimum buttressed walls than the overturning constraint. Finally, as for the results derived from the optimization procedure, a more suitable rule of thumb to dimension the footing thickness of the footing is proposed.
\end{abstract}

\section{Keywords}

Structural design; Heuristics; Harmony search; Cost optimization; Concrete structures

${ }^{1}$ Graduate Research Assistant, Dept. of Transport Infrastructure and Engineering, Universitat Politècnica de València, 46022 Valencia, Spain. E-mail: framomo4@upvnet.upv.es

${ }^{2}$ Graduate Research Assistant, Institute of Concrete Science and Technology (ICITECH), Universitat Politècnica de València, 46022 Valencia, Spain. E-mail: tagarse@cam.upv.es

${ }^{3}$ Associate Professor, Institute of Concrete Science and Technology (ICITECH), Universitat Politècnica de València, 46022 Valencia, Spain. E-mail: jvmartia@cst.upv.es

${ }^{4}$ Associate Professor, Institute of Concrete Science and Technology (ICITECH), Universitat Politècnica de València, 46022 Valencia, Spain. Corresponding author. Phone +34963879563; Fax: +34963877569; E-mail: vyepesp@cst.upv.es 


\section{Introduction}

The common procedure for economic structure design adopts the cross-section dimensions and material grades restricted by professional practice. To satisfy the limit states prescribed by codes, it is necessary to analyze the stresses and compute the required reinforcement. As the initial dimensions or material grades could be excessive or insufficient, a trial-and-error approach is generally used. Therefore, the cost of the structure depends on the experience of the designer. To achieve an economic wall design, a more efficient process, as well as an accurate model, is needed. Cost efficient design is not a straightforward method, as it is determined by boundary conditions such as type of fill, base-friction angles, soil foundation bearing capacity and surcharge loads. As an alternative to this procedure, either exact or heuristic optimization approaches can be used.

Metaheuristic algorithms have proven their efficiency and versatility in solving large-scale and highly nonlinear optimization problems [1]. There has been a tremendous amount of research in metaheuristics during the last years, most of them nature-inspired on swarm intelligence, biological systems, physical and chemical systems [2]. Several heuristic search algorithms belonging to this category are harmony search (HS), simulated annealing (SA), threshold accepting (TA), genetic algorithms (GA), ant colonies (ACO), particle swarm optimization (PSO), tabu search (TS), flower pollination algorithm (FPA), teaching-learning based optimization (TLBO), among others. Rajeev and Krishnamoorthy [3] pioneered by applying genetic algorithms to the optimization of weight in steel structures, followed by Coello et al. [4], who applied GA to Reinforced Concrete (RC) beams. Sarma and Adeli [5] reviewed major works on cost optimization of RC structures published in the past few decades. The robustness of ACO, GA, HS, PSO, SA, TS, FPA, and TLBO has been investigated through five benchmark steel frame designs [6-8]. The results showed the benefits of incorporating intensification and diversification to navigate the large variable spaces presented in these optimization problems effectively.

Other RC structures have been the subject of numerous optimization studies. The optimum design of frame structures was performed by using the Eagle Strategy with Differential Evolution [9]. Kripka et al. [10] used SA to minimize the costs of the beams in RC buildings using a grid model. Carbonell et al. [11] aimed to achieve the most economical design of RC road vaults by a multi-start global best descent local search, a meta-SA and a meta-TA. Prestressed concrete precast road bridges were optimized with hybrid SA [12] and the hybrid glowworm swarm algorithm [13]. De Medeiros and Kripka [14] adopted HS to minimize the cost of RC columns according to different environmental impact assessment parameters. Camp and 
Assadollahi [15] used big bang-big crunch (BB-BC) technique to optimize RC footings. Luz et al. [16] used hybrid stochastic hill climbing algorithms with a neighborhood move based on the mutation operator from the genetic algorithms to minimize the cost of RC open abutments of road bridges. García-Segura et al. [17] proposed a Hybrid HS for the design of post-tensioned concrete box-girder pedestrian bridges. Yepes et al. [18] used a multiobjective SA to optimize a RC I-beam. Recently, García-Segura and Yepes [19] proposed a multiobjective HS to optimize a post-tensioned concrete box-girder road bridge.

Optimum cantilever retaining walls have recently been studied considering different metaheuristics. Recent works on retaining walls studied through SA [20] and TA [21] strategies compared the effect of base soil friction angles on the design parameters variations. Talatahari and Sheikholeslami [22] used an enhanced charged system search method to optimize the cost of gravity and RC retaining walls. Sheikholeslami et al. [23] used the Hybrid Firefly algorithm to minimize the cost of cantilever retaining walls. Swarm intelligence techniques such as particle swarm optimization (PSO), accelerated PSO, (APSO), firefly algorithm (FA) and cuckoo search (CS) were compared to find the influence of surcharge load and backfill slope on the cost and weight optimum cantilever walls [24]. Bekdaş [25] proposed a HS strategy for posttensioned axially symmetric cylindrical RC walls. Despite there being limited research on geotechnical engineering optimization problems, the studies of Khajehzadeh et al. [26], who studied the design of gravity-retaining walls subjected to seismic loading, are also worth mentioning.

If the wall is taller than $9 \mathrm{~m}$, the thickness of the stem becomes greater, as well as the volume of concrete. To make the stem lighter, a ribbed plate (buttressed) is preferred to a solid plate. Earth-retaining buttressed walls made of reinforced concrete (RC) are common structures in civil engineering. Various design factors influence the appearance and, consequently, the performance with regard to life span, cost or environmental impact [27]. Earth-retaining buttressed walls for roads and building structures are analyzed in this study. The method followed in this paper consists of a computer module evaluation of geometric and steel reinforcement according to the optimization variables. The cost of every solution is computed, and the limit states are checked. The hybrid HS together with a TA strategy is used for a cost optimization and a design parametric study. Our paper is divided into five sections: (1) formulation of the optimal design problem; (2) the structural evaluation; (3) the proposed HSTA algorithm and calibration; (4) results obtained and discussion of the numerical experiments; and (5) conclusions. 


\section{Optimization Problem Definition}

The structural concrete problem proposed consists of an economic optimization. The objective function cost $(C)$ to be minimized is defined in Eq. (1). The objective function considers the unit prices $p_{i}$, and the measurements $\left(m_{i}\right)$ of the eight cost units in which the wall is divided. Basic prices are given in Table 1 and correspond to prices considered in an earlier study of earth-retaining walls by Yepes et al. [20]. The prices included the materials, formwork, excavations and fill works. In addition, the structure may satisfy the constraints defined as boundary conditions (viz. serviceability and ultimate limit states). The major computational effort lies in the evaluation of the ULS and SLS constraints. This study restricts the problem to feasible solutions, so no penalty functions are used.

$$
\mathrm{C}(\vec{x})=\sum_{i=1, r} p_{i} \cdot m_{i}
$$

\subsection{Design variables}

The buttressed retaining wall is defined by 32 design variables, which are discrete to adapt to real cases. These variables correspond to the geometry, the concrete grades and the passive reinforcement of the wall. The geometric variables are the thickness of the stem $(b)$, the thickness of buttresses $\left(e_{\mathrm{c}}\right)$, the thickness of the footing $(c)$, the length of the toe $(p)$, the length of the heel $(t)$, and the distance between buttresses $(d)$. The concrete and steel types are the variables considered for the materials. Concrete HA-25 to HA-50 is considered in discrete intervals of $5 \mathrm{MPa}$. Steel types B500S and B400S are considered. The remaining 24 variables consider the set-up of reinforcement, as shown in Fig. 1 and Fig. 2. The diameter and the number of bars define the reinforcement. Three reinforcement flexural bars defined as $A_{1}, A_{2}$ and $A_{3}$ contribute in the main bending of the stem. The vertical reinforcement of foundation in the rear side of the stem is given by $A_{4}$, up to a height $L_{1}$. The secondary longitudinal reinforcement is given by $A_{5}$ for shrinkage and thermal effects in the stem. The longitudinal reinforcement of the buttress is given by $A_{6}$. The area of reinforcement bracket from the bottom of the buttress is given by $A_{7}$ and $A_{8}$. The upper and bottom heel reinforcement are defined by $A_{9}$ and $A_{11}$ and the shear reinforcement in the footing by $A_{12}$. The longitudinal effects in the toe are defined by $A_{10}$. The set of combinations of the values for the 32 variables constitutes the space of solutions.

\subsection{Design parameters}

The data fixed in the optimization search are the design parameters of the problem. They are kept constant in the optimization process, and are modified for the design parametric study in Section 6. Ground and earth 
fill properties, safety coefficients and total height of the wall form the parameters. Figure 3a depicts the main design parameters. The height of the wall and the depth of soil in front of the wall are given by $H$ and $H_{2}$, respectively. The maximum bearing pressure is the soil foundation ultimate bearing capacity divided by the bearing capacity factor of safety. As the maximum bearing pressure of the soil is fixed for a case study, this study proposes a parametric study to investigate the sensitivity of the solution to this design parameter. The maximum bearing pressure for serviceability conditions is represented by $\sigma$, the basefriction coefficient is $\mu$ and the backfill slope on the top of the stem is $\beta$. The density, internal friction angle and the friction angle determining the angle of earth pressure are given by respectively $P(\gamma, \phi, \delta)$. The roughness between the wall and the fill is determined by a fraction of $\phi$. The three types of fills $\left(F_{1}, F_{2}, F_{3}\right)$ used, based on a previous study [28], are described in Table 3. This kind of wall requires the placement of expansion joints, as they affect the distribution of strengths in the plate of the stem. The expansion joints are located every three spans of the buttresses, as illustrated in Figure 1. The distance between the buttresses and the expansion joints is fixed to $0.82 \mathrm{~m}$ so as to obtain equal bending moments in the plate of the stem. The parameter $q$ corresponds to the uniform surface loading on top of the fill. The cohesion of the ground is considered to be 0 .

\subsection{Structural constraints}

The structure is checked according to the Spanish Structural Concrete Code EHE-08 [29]. The flexural and shear state limits as well as the cracking state limit are considered. The hyperstatic structure is checked according to the method of Huntington [30]. The flexural moment is obtained considering a T-shaped crosssection (Fig. 1). The cross-section in the top of the stem is relatively small, so the horizontal bending is similar to a continuous slab between supports. Fig. 3 illustrates the dimensions of the wall.

To verify the limit states of the structure, calculation of the active earth pressure is required [31]. The active pressure depends on the fill and surface loads. The key forces considered in the wall analysis are the weight of the wall $\left(W_{1}\right)$, the fill loading on the heel $\left(W_{2}\right)$, the earth pressure $\left(P_{1}\right)$, the surface load $(Q)$, the weight on the front toe $\left(W_{3}\right)$, and the passive resistance in front of the toe $\left(R_{\mathrm{p}}\right)$. The load on the buttresses is obtained from the pressure distribution over the stem multiplied by the distance between buttresses.

The stem is subject to both flexural and shear efforts diminished by the effect of every buttress that is placed at a distance $d$ (Fig. 1). Unlike the top of the stem that acts as a cantilever, the bottom of the stem is subject 
to considerable coercion from the footing and the bottom of the buttress in the rear side of the stem. The bending moments in the half section between the buttresses are given by $\mathrm{M}_{1}$ and $\mathrm{M}_{2}$ :

$$
\begin{gathered}
M_{1}=-0.03 p_{1} d(H-c) \\
M_{2}=-0.0075 p_{1} d(H-c)
\end{gathered}
$$

where $p_{1}$ is the pressure over the slab on the upper side of the footing, $M_{1}$ is the bending moment in the connection of the stem to the footing, and $M_{2}$ the bending moment in the stem at a distance equal to $(\mathrm{H}-\mathrm{c}) / 4$ from the footing (Fig. 3b). Provided that the distance between buttresses is lower than half the height, the shear strength $(v)$ in the connection of the plate to the footing is defined as:

$$
v=0.4 p_{1} l
$$

The bending moments in every span of the stem are considered according to Huntington [30]. The method considers a trapezoidal pressure distribution (Fig. 3b), where the maximum value is half the maximum pressure $P_{l}$ in the upper side of the foundation [31].

The buttresses are modeled as a cantilever of varying sections. However, as there is a varying depth in the cross-section, several considerations are needed. The bending moments and shear stress are given only by the horizontal reaction, as the vertical reaction is negligible. The calculation of the bending stress in any horizontal T-shape cross-section is obtained by the effective width, as indicated in CED-FIB Model Code [32]. Calavera [33] gives the equations to evaluate the mechanical capacity to flexure and shear. Besides, Calavera considers the limitations of the Spanish EHE Structural Concrete Code [29]. Overturning, sliding and ground stresses are the three limit states of the wall and are checked considering the effect of the buttresses. The basic expressions are given in Eqs. (7)-(9). As regards the overturning condition, Eq. (7) states that the favorable overturning moments are high enough compared to unfavorable overturning moments. In this expression, $M_{\mathrm{of}}$ is the total favorable overturning moment given by Eq. (8); $M_{\mathrm{ou}}$ is the total unfavorable overturning moment defined by Eq. (9), and $\gamma_{\text {ou }}$ is the overturning safety factor considered as 1.8 for frequent events.

$$
\begin{gathered}
M_{o f}-\gamma_{t o} M_{o u} \geq 0 \\
M_{o f}=N^{\prime}\left(\frac{B}{2}-e_{p}\right)-\left(E_{p}\left(H_{t}-h^{\prime}\right)\right. \\
M_{o u}=E_{h} * h_{e}-E_{v}\left(\frac{B}{2}-f\right)
\end{gathered}
$$

The reaction against sliding is defined by Eq. (10), where $N^{\prime}$ is the total sum of weights of the wall and ground located over the toe and the heel; $\mu$ is the base-friction coefficient, and $E_{\mathrm{p}}$ is the passive resistance 
in front of the toe, obtained by Eq. (11) [31]. The sliding moment is produced by the horizontal component of the earth pressure because of the negligible effect of the vertical component.

$$
\begin{gathered}
R=N^{\prime} \mu+E_{p} \\
E_{p}=\frac{1}{2 \gamma\left(H_{t}^{2}-\left(H_{t}-c\right)^{2}\right)}(1+\sin \varphi) /(s-\sin \varphi)
\end{gathered}
$$

The calculations are performed per linear meter, including service and ultimate flexure and ultimate shear. The acting shear is compared to the two ultimate values. Both flexural and shear minimum amounts of reinforcement, and the geometrical minimum, are examined. Once the 32 variables describing a wall solution are chosen, then geometry, materials and passive reinforcement become fully defined. A 50\% increase in earth pressure is checked not to cause a ground reaction force twice as high as the maximum bearing pressure, according to Calavera [33].

\section{Proposed harmony search strategy}

Harmony Search (HS), proposed by Geem et al. [34], is a population-based stochastic optimization approach, which establishes an analogy to attaining the best musical harmony. Researchers have proposed various HS variants in the past decade to improve the performance of the basic HS [35,36]. Manjarres et al. [37] analyzed the main characteristics and reviewed the applications where the algorithm was effectively used. They highlighted the good convergence regardless of the initialized values and the potential to merge the characteristics of a group of solutions by simply tuning the values of its probabilistic parameters. While Genetic Algorithm considers only two vectors called parents to generate a new solution or offspring, HS takes into account all the solutions in the harmony memory. Saka et al. [38] exposed that HS is a special case of the Evolutionary Strategy (ES). However, whereas HS allows selection of the design variables from a discrete set, ES is a continuous optimization method. Besides, the local strategy is different, as the new value of a design variable is obtained by applying a normally distributed based mutation in ES. This paper employs a Hybrid Harmony Search with Threshold Acceptance (HSTA) proposed by García-Segura et al. [17]. TA, proposed by Dueck and Scheuer [39], minimizes as the search grows. HSTA combines the effectiveness of HS in the search of a large variable space with the local search of TA. As it was shown in García-Segura et al. [17], for a 130 m deck length, HSTA improved the quality of solution about $8 \%$ compared to HS. The metaheuristic algorithms provide a diversification and intensification balance to global search, and converge to good solutions. Fig. 4 depicts the algorithm structure. The steps of the algorithm can be summarized as follows: 
Step 1. The algorithm parameters are assigned: harmony memory size (HMS), harmony memory considering rate (HMCR), harmony memory probability (HMP), pitch adjusting rate (PAR), the maximum number of improvisations without improvement (IWI), and the threshold iterations (TI). A design variable pool is constructed for each design variable.

Step 2. Harmony memory matrix (HM) is initialized with random values of the design pool. First, the algorithm creates $\mathrm{n}_{\mathrm{HMS}} * \mathrm{HMS}$ random feasible solutions. Then, HM is filled with the best HMS solution vectors.

$$
H M=\left(\begin{array}{ccc|c}
x_{1}^{1} & \cdots & x_{n}^{1} & C\left(x^{1}\right) \\
\vdots & \ddots & \vdots & \vdots \\
x_{1}^{H M S} & \cdots & x_{n}^{H M S} & C\left(x^{H M S}\right)
\end{array}\right)
$$

where $x^{j}$ is the solution vector, $n$ is the number of variables and $C$ is the cost of the solution.

Step 3. A new harmony vector is improvised. Values of the other decision variables can be chosen from a set of possible values in the design variable pools with the probability equal to (1-HMCR) (Eq. (13)). Otherwise, each value of the new solution has a probability of HMCR to be chosen from the HM (Eq. (14)). For the final case, the value is selected from a solution vector according to its probability, defined by Eq. (15). The probability of a solution depends on its position in the ranking $(j)$, the first solution being the best one. HMP is a parameter between 0 (corresponding to deterministic choice) and 1 (corresponding to simple random sampling). Afterwards, the pitch adjusting determines whether the value is modified one position up or down with a probability PAR (Eq. (16)).

$$
\begin{gathered}
X_{i}^{\prime} \in X_{i} \text { with probability }(1-H M C R) \\
X_{i}^{\prime} \in\left\{x_{i}^{1}, x_{i}^{2}, \ldots, x_{i}^{H M S}\right\} \text { with probability HMCR } \\
p(j)=\frac{H M P^{j-1} *(1-H M P)}{1-H M P^{H M S}} \\
X_{i}^{\prime} \in x_{i}^{j} \pm 1 \text { with probability } P A R
\end{gathered}
$$

Step 4. Harmony memory matrix is updated. The new solution replaces the worst harmony if its function value improves upon the worst one.

Step 5. Steps 3 and 4 are repeated until the iterations without improving the best harmony reach a maximum number of iterations (IWI).

Step 6. TA carries out a local search around the best solution. Each iteration modifies a percentage of the variables $\left(P_{\text {var }}\right)$. Threshold accepting accepts worse solutions when the increment is lower than a threshold value $(\Delta T)$. Initially, a $1 \%$ increment in the function value is accepted. This threshold value is reduced 
gradually to zero during half of the TI. After that, only better solutions are accepted. TA performs a number of TI. The vector solution updates the best solution if there is an improvement.

\section{Results of the optimization procedure}

The adjustment of the HSTA parameters is carried out by an experimental process considering the parameters of Table 4. The calibrated parameters were obtained as a result of several test runs. The five best results are shown in Table 5. A typical evolution of cost from the initial solution to optimum results is depicted in Fig. 5. The initial solution is obtained through a random choice of the values of the variables in the discrete range between upper and lower bounds. After a feasible solution is obtained, the harmony search reduces the cost to about $60 \%$ of the initial solution. Then, TA carries out a local search variation of a fixed percentage (30\%) of variables selected randomly. The algorithm was performed nine times for every case to obtain the mean, standard deviation and minimum values of the random results. This ensures the solution quality for each objective according to the methodology proposed by Payá-Zaforteza et al. [40], based on the extreme value theory.

\section{Main factors affecting optimum walls}

There is a number of factors affecting the design of optimum buttressed retaining walls. The main factors are described in this section, leading to a parametric study in the following section. The main factors affecting the design are (1) the height of the wall from foundation to the top of the stem, (2) the base-friction coefficient, (3) the density and angle of internal friction of the type of fill, (4) the soil foundation bearing capacity, (5) the inclination of the earth pressure determined by the wall-fill friction angle, and (6) the passive earth pressure in front of the toe. This section analyses the base-friction coefficient, wall-fill friction angles and passive earth pressure in front of the toe. Section 6 describes a parametric study of the total height of the wall, type of fill and bearing capacity of the foundation, considering the aforementioned parameters as fixed. The average values of the optimum walls are considered herein.

The base-friction coefficient $(\mu)$ is one of the factors affecting a cost-efficient design. Fig. 6 illustrates a cost variation following upward parabolic trends for the total height of the wall. This trend continues in the different base-friction angles of $25^{\circ}, 30^{\circ}, 35^{\circ}$ and $40^{\circ}$. A standard case corresponds to the type of soil $F_{2}$, and 0.3 MPa maximum bearing pressure. The results show that the costs increase as the wall-friction angle decreases. The base-friction angles of $25^{\circ}$ and $30^{\circ}$ significantly influence the cost as the height increases. A tangent of $25^{\circ}$ in wall-fill friction results in an increase of $15.92 \%$ for a wall of $11 \mathrm{~m}$, compared to a base- 
friction coefficient of $40^{\circ}$. A tangent value of $30^{\circ}$ shows an increase of $10.10 \%$ for the same height compared to a tangent of $40^{\circ}$ in base-friction. Higher base-friction angles, i.e. $35^{\circ}$ and $40^{\circ}$ do not exhibit differences as regards cost-optimal designs. It is worth mentioning that a standard angle of $30^{\circ}$ is usually considered due to the complexity of a more precise value from geotechnical data. An internal angle of friction of the fill of $30^{\circ}$ is considered for the subsequent design parametric study.

The wall-fill friction angle that causes the inclination of the earth pressure is the next influential factor on the cost. As stated previously, this analysis considers a standard case with an internal angle of friction of the fill $\phi=30^{\circ}$, a type of fill $F_{2}$ defined in Table 3 and $0.3 \mathrm{MPa}$ as maximum bearing pressure. Fig. 7 shows the influence of the wall-fill friction angles $\delta$, which corresponds to $0^{\circ}, 1 / 3 \phi\left(10^{\circ}\right)$ and $2 / 3 \phi\left(20^{\circ}\right)$. Costs exhibit a steady divergence among such angles as the height increases. Considering a passive pressure angle of $10^{\circ}$, the wall-fill friction angles of $10^{\circ}$ and $20^{\circ}$ show an average cost reduction in the highest walls (9$16 \mathrm{~m})$ of $5 \%$ and $11 \%$ respectively, compared to the passive earth pressure angle of $0^{\circ}$.

Fig. 8 depicts results for every height and wall-fill friction angles of $20^{\circ}, 10^{\circ}$ and $0^{\circ}$ considering a passive earth pressure of $0^{\circ}$. Considering the aforementioned standard case, walls from 9-16 $\mathrm{m}$ show lower costs in $10^{\circ}$ and $20^{\circ}$ angles compared to a wall-fill friction angle of $0^{\circ}$. In this case, the wall-fill friction angles of $10^{\circ}$ and $20^{\circ}$ show an average cost reduction in the highest walls (i.e. 9-16 m) of $6 \%$ and $9 \%$ respectively, compared to passive earth pressure angle $0^{\circ}$. In the shortest walls, the differences in cost are barely $1 \%$ for an angle of passive pressure of $10^{\circ}$, and $2 \%$ for an angle of $0^{\circ}$. The results explain the preference in project design for wall-fill friction angles different to $0^{\circ}$ as the height increases. However, the most relevant factor that affects this parameter is the roughness of the wall surface, usually considered smooth. Design based on angles different to $0^{\circ}$ is generally not justified; therefore the parametric design in this study considers $0^{\circ}$. A conservative passive earth pressure angle of $0^{\circ}$ is taken so as to ignore such pressure in front of the toe.

An influential factor in retaining walls is the safety against overturning. A value of 1.8 is generally used as a safety coefficient against overturning. Using this coefficient of overturning, the condition factors obtained for this study remain between 1.07-2.49. Note that a factor of one implies strict compliance. Such a range reveals that overturning is not a major constraint for optimum walls. On the other hand, safety against sliding is a greater constraint. Considering a safety coefficient against sliding of 1.5 , the range of sliding factors obtained barely exceeds one. This indicates that safety against sliding is relevant for optimum walls, compared to the overturning constraint. 


\section{Design parametric study}

The design parametric study shows the variation of relevant variables according to the fill, height and bearing capacity of the foundation. This approach enables to investigate the sensitivity of the solution to these parameters. It gives rise to general recommendations that can be useful for the day-to-day design of buttressed earth-retaining walls with a restrictive cost at early design stages. A set of 13 wall heights ranging from 4-16 $\mathrm{m}$ are studied. Besides the total height, the parameters considered are the maximum bearing pressure for serviceability conditions $\sigma$; considering $0.2,0.3$ and $0.4 \mathrm{MPa}$ and the types of fill $F_{1}, F_{2}$ and $F_{3}$ respectively defined in Table 3. All parameters considered account for a set of 117 different wall combinations performed nine times for statistical validity. A total of 1053 walls were calculated. The remaining relevant parameters described in Section 5 are considered constant values, as described in Table 6. MATLAB software was used in an Intel Core i5 processor at $3.6 \mathrm{GHz}$. An average of 12.5 minutes was necessary for each iteration.

Fig. 9 shows the cost variation for a total of 117 walls studied based on averaged values. The cost results are sensitive to the soil foundation bearing capacity in all types of fills in a different manner as the height increases. Coarse granular fills $F_{1}$ and fine soils of low plasticity $F_{3}$ exhibit greater sensitivity than mixed soils $F_{2}$. An average increment of cost of $10.15 \%$ in $F_{1}$ is observed, between grounds of 0.2 and of $0.4 \mathrm{MPa}$ maximum bearing pressure, followed by $9.72 \%$ and $4.80 \%$ in $F_{3}$ and $F_{2}$, respectively. Note that such increments correspond to average values for walls taller than $10 \mathrm{~m}$, the height from which differences in cost become relevant. Concerning the practical use, fill $F_{2}$ and $0.2 \mathrm{MPa}$ presents a parabolic expression equal to $13.946 x^{2}-61.459 x+373.59$ with a value for $R^{2}$ equal to 0.9995 . The expression $16.837 x^{2}-61.039 x$ +332.92 with $\mathrm{R}^{2}$ equal to 0.9982 explains the increment for the most economic solutions that correspond to fill $F_{3}$ (granular soil with fines) with $\sigma$ equal to $0.2 \mathrm{MPa}$. Results show that the maximum bearing pressure is one of the main key parameters affecting the cost of optimum walls mainly in coarse granular fills $F_{1}$ and $F_{3}$ and less in $F_{2}$.

Table 7 summarizes the features of the best solutions for a $7 \mathrm{~m}$ height in $F_{1}$. The best cost solution $C$ corresponds to 0.3 $\mathrm{MPa}$. As regards the buttresses, the minimum results show that thickness of the stem $b$ and the footing $c$ are unaffected by the bearing capacity considered. As for the distance between buttresses $d$, the most economical solution grants a larger distance between buttresses. The toe for the case of $0.2 \mathrm{MPa}$ maximum bearing pressure has a slightly longer toe $p$ than the 0.3 and $0.4 \mathrm{MPa}$ counterparts. It is worth noting that the optimal solution in $0.4 \mathrm{MPa}$ implies a shorter heel with a thicker footing height $c$. The 
amount of reinforcement in the stem $\left(R_{\mathrm{st}}\right)$, is similar in the three bearing capacities. However, in this specific case the footing exhibits a $42 \%$ greater steel amount $\left(R_{\mathrm{ft}}\right)$ in $0.2 \mathrm{MPa}$ grounds than in $0.3 \mathrm{MPa}$ grounds, while $0.4 \mathrm{MPa}$ grounds present $15 \%$ greater amount than in $0.3 \mathrm{MPa}$. As expected, the ratio of steel reinforcement per cubic meter of concrete in the whole wall $\left(w_{s t}\right)$ rises as the bearing capacity decreases.

Table 8 depicts the mean values of the three bearing capacities and the difference in cost respect to the 0.4 $\mathrm{MPa}$ ground. It can be seen that the greatest differences of $\sigma$ are obtained from 11 meters' height and above. This can be explained by a greater demand for stability in the lowest maximum bearing pressure considered (0.2 MPa), as the length of the footing (heel, $p+$ toe, $t$ ) is only slightly larger (see Table 7$)$.

Fig. 10 shows the variation in the total volume of concrete per linear meter for the interval of heights of the retaining wall. The results show the increment in volume of concrete between $F_{1} F_{2}$, and $F_{3}$ fills with the height. The type of concrete obtained for the best solutions is $25 \mathrm{MPa}$. For a minimum cost solution, there is a need for higher amount of concrete in $F_{3}$ fill types as its condition of low plasticity soil. The parabolic expression for $F_{3}$ fill type and $0.4 \mathrm{MPa}$ maximum bearing pressure adjusts to $0.1039 \mathrm{x}^{2}-0.2543 \mathrm{x}+0.7447$ with $\mathrm{R}^{2}=0.9909$. The rest of $\sigma$ exhibit a less accurate adjustment in walls from $12-16 \mathrm{~m}$ height. Fills $F_{1}$ and $F_{2}$ present less accuracy in trend as the use of greater ratio of steel per $\mathrm{m}^{3}$ becomes necessary in the cross-section of the highest walls. The variation adjusts to the parabolic curves for the nine cases studied. The volume of concrete for the lower cost corresponds to fill type $F_{1}$ and $0.4 \mathrm{MPa}$, as expected, and adjusts to $0.0689 \mathrm{x}^{2}-0.2526 \mathrm{x}+1.4274$ with $\mathrm{R}^{2}=0.9923$.

Fig. 11 illustrates the variation of thickness of the stem, for the range of heights studied. Values show almost negligible variation of the thickness for the lowest stem belonging to the lowest walls, for the different type of fill and ground stress. The average values show a linear variation in the range of 6-10 $\mathrm{m}$ height and adjusts to the expression $\mathrm{y}=0.0201 \mathrm{x}+0.1212$. Thickness values range from $0.25-0.57 \mathrm{~m}$. Conversely, granular soils $F_{2}$ and fine soils $F_{3}$ allow for thinner stems than do $F_{1}$. Values range from $0.25-0.3 \mathrm{~m}$ in $F_{2}$ and up to $0.45 \mathrm{~m}$ in $F_{3}$.

Fig. 12 shows the variation of thickness of the footing. Similar to cantilever retaining walls, the footing of buttressed walls generally adopts a thickness between $1 / 12-1 / 10$ of the wall height, according to Calavera's recommendations [33]. Values decrease from a uniform value of $0.30 \mathrm{~m}$ for all types of fill in the shortest walls to up to $0.90-1.11 \mathrm{~m}$ in higher walls, subject to the type of fill. The general trend shows that higher walls exhibit a relative decrease of thickness per meter of height. Higher values correspond to fills $F_{1}$ 
showing little difference subject to the maximum bearing pressure. The types of fill $F_{2}$ and $F_{3}$ show similar values for $\sigma$. The expression for $F_{3}$ equals to $0.0585 \mathrm{x}+0.2909$. Walls between $4-6 \mathrm{~m}$ height exhibit similar footing thickness, as there is a minimum thickness required for bending and shear stress constraints.

Fig. 13 outlines the total length of the footing. The length on average in fill $F_{1}$ exhibits relevant differences for all the heights subject to the three bearing capacities studied. Such differences range up to almost $2 \mathrm{~m}$ length between $0.2-0.3 \mathrm{MPa}$. The proportion of the toe increases as the height increases, due to more demanding ground stress conditions. It is worth noting the difference for $0.2 \mathrm{MPa}$ ground stress compared to the 0.3 and $0.4 \mathrm{MPa}$ cases, as a way to adapt to lower foundation stresses. The length of the footing in fill $F_{3}$ shows an increasing difference as the height increases. Values range from $1.05-7.60 \mathrm{~m}$ in $F_{3}$. The average function adjusts to $0.0296 \mathrm{x}^{2}+0.1985 \mathrm{x}-0.31$ with $R^{2}=0.998$. All fill types exhibit greater sensitivity of the length of the footing to the maximum bearing pressure. It is worth noting the influence of fill $F_{2}$ for slip resistance as greater length of the footing is required in $0.2 \mathrm{MPa}$ grounds. The expression now equals $0.0602 x^{2}-0.3442 x+1.4642$ with a regression coefficient of 0.9914 . Considering such values, fill type $F_{1}$ requires larger sizes of footing than do $F_{2}$ and $F_{3}, 24 \%$ and $9 \%$ respectively. It is observed that the length of the toe in the footing is clearly longer for $0.2 \mathrm{MPa}$ maximum bearing pressure compared to the 0.3-0.4 MPa cases with regard to adaptation to lower ground stresses.

As regards the thickness of the buttresses, walls are more toe-heel compensated and require less thickness for the buttresses in fill type $F_{1}$, which results in similar cost solutions. Fig. 14 depicts the thickness of the buttresses, $e_{\mathrm{c}}$, which remains in the interval of $0.25-0.30 \mathrm{~m}$. It is worth noting that fill $F_{1}$ exhibits a decreasing thickness for $0.4 \mathrm{MPa}$ grounds, as the distances among buttresses are shorter in $F_{1}$. Fig. 15 shows that the distance between buttresses obtained is influenced by the bearing capacity of the foundation as the height rises. The distance adapts to the recommended values of $1 / 3 H$ to $1 / 2 H$, adopted in the usual practice according to Calavera [33] for walls under $10 \mathrm{~m}$. The higher walls can be narrowed to shorter distances; a stricter boundary defined by the expression $y=0.378 x+0.8$ as upper bound and $y=0.19 x+1.15$ as lower bound. These boundaries narrow the recommendation to an interval between $1 / 5 H$ and $1 / 3 H$.

Fig. 16 shows the variation of steel used per volume of concrete in the wall for the three types of fill and all the heights studied. All results used type of steel B500S. Values range from $30-80 \mathrm{~kg} / \mathrm{m}^{3}$ of reinforcement. Fig. 17 shows the variation of steel used per volume of concrete in the stem, including the buttress. The linear performance obtained is worth noting in the ratio of reinforcement of the stem, compared to that in the footing (Fig. 18). The type of fill $F_{1}$ in $0.2 \mathrm{MPa}$ grounds exhibits a steadier linear 
progression in the reinforcement ratio of the footing (equal to $7.1043 \mathrm{x}-5.1616)$ than in the stem $(\mathrm{y}=3.2959 \mathrm{x}$ $+11.459)$. The values of all the ratios fall in the range of $30-65 \mathrm{~kg} / \mathrm{m}^{3}$ in the stem and between $20-100$ $\mathrm{kg} / \mathrm{m}^{3}$ in the footing.

Analysis of the ratio of $\mathrm{kg}$ of steel per volume of concrete for the stem and the footing concluded that the type of fill affects differently the ratio of reinforcement needed in each part of the wall. Therefore, considering the whole wall, the ratio exhibits a difference between types of fill. Walls in $F_{1}$ need for a higher rate of reinforcement than $F_{2}$ and $F_{3}$ both in the stem and the footing. The fill $F_{3}$ has a ratio of 42 against the fill $F_{1}$ with a ratio 48 in the whole wall. On the other hand, $F_{3}$ shows a more balanced ratio between the stem and the footing, with a difference of $8 \%$, while $F_{1}$ shows a difference of $16 \%$.

It worth noting that the dimensions of the wall can be reduced compared to the usual rules in professional practice. Optimized feasible walls can reach lower values for the thickness of the footing than the dimensioning values $1 / 12 H$ and $1 / 10 H$ prescribed by Calavera [33]. As for the distance between buttresses and same objective, the highest walls could be straightened by shorter distances between buttresses than the values proposed by Calavera [33]; a narrower boundary between $1 / 5 H$ and $1 / 3 H$ can be achieved (Fig. $15)$.

\section{Conclusions}

A hybrid harmony search (HSTA) algorithm is used for optimizing the cost of buttressed earth-retaining walls. The calibration of the variables involves a variation of variables of $30 \%$ and a harmony memory size of 200 initial solutions. From the starting 800 solutions, the first quartile of 200 best solutions is taken. This first filter allows us to extract a good set of solutions to begin with. The algorithm includes a threshold accepting strategy that improves solutions by incremental cost reduction for the final accepted solution. The results show that the base friction coefficient as well as the wall-fill friction angle are crucial factors affecting the design. A 30 tangent value for the base friction and a 0 wall-fill friction angle was used for a design parametric study with a set of 13 wall heights. This study shows the variation of relevant variables according to the fill, height and bearing capacity of the foundation. Optimum walls depict a good parabolic correlation with the total height of the wall. Average expressions for the cost, the total volume of concrete, as well as the relevant geometric variables were derived, which can be useful for the day-to-day design of buttressed walls. In that sense, the analysis reveals that the dimensions of the thickness of the footing can be reduced compared to the usual rules in professional practice. Thus, upper bounds of $1 / 15 H$ and $1 / 20 H$ 
for the thickness are proposed with a cost objective. The highest walls could be straightened by shorter distances between buttresses than the values used usually as practical rules; a narrower boundary between $1 / 5 H$ and $1 / 3 H$ can be achieved. The cost results are sensitive to the maximum bearing pressure for each type of fill in a different manner as the height increases. The ratio of reinforcement per volume of concrete for the whole wall and each single part is a relevant number for the comparison among other types of retaining walls. To conclude, the methodology described is flexible and open to further modifications and extensions, so that costs can be reduced in RC structural designs. However, designing real RC structures is a complex process that still requires engineering judgment. Future research using the algorithm might include a sensitivity analysis of more parameters and a comprehensive analysis of additional constraints, such as different distributions of ground-bearing pressures and full slip-circle analysis and other earth retaining structures, such as mechanically stabilized earth walls.

\section{Acknowledgments}

This research was funded by the European Institute of Innovation and Technology under grant agreement n 20140262 Low Carbon Strategy in the Construction Industry (PGA_APED0094_2014-2.1-278_P06610) and the Spanish Ministry of Economy and Competitiveness along with FEDER funding (Project BIA2014-56574-R).

\begin{tabular}{|ll|}
\hline Notation & \\
$b$ & stem thickness \\
$h$ & footing thickness \\
$m_{i}$ & stem height \\
$p$ & wall measurement \\
$p_{i}$ & toe length \\
$q$ & unit prices \\
$t$ & uniform surface loading on top of the fill \\
$z$ & heel length \\
$v_{c}$ & footing length \\
$x_{1}, \ldots, x_{n}$ & total volume of concrete \\
$z$ & design variables \\
$A_{1}, \ldots, A_{12}$ & length of the footing \\
$R_{\mathrm{st}}$ & reinforcement variables \\
$R_{\mathrm{ft}}$ & reinforcement of the stem \\
$R_{t}$ & reinforcement of the footing \\
$C$ & total weight of steel \\
$F$ & wall cost \\
$F_{1}, F_{2}, F_{3}$ & objective function \\
$H$ & types of fills \\
$H_{2}$ & total height of the wall \\
$M_{o f}$ & foundation depth \\
\hline
\end{tabular}




\begin{tabular}{|ll|}
\hline$M_{o u}$ & total favorable overturning moment \\
$P(\gamma, \phi, \delta)$ & earth pressure \\
$P_{p}$ & passive earth pressure on the toe \\
$Q$ & Surface loading on top of the fill \\
$\alpha$ & angle slope of the buttress \\
$\gamma$ & density of the fill \\
$\gamma_{f s}$ & safety coefficient against sliding \\
$\gamma_{f o}$ & safety coefficient against overturning \\
$\phi$ & internal friction angle \\
$\delta$ & wall-fill friction angle \\
$\sigma$ & maximum bearing pressure \\
$\mu$ & base-friction coefficient \\
\hline
\end{tabular}

\section{References}

[1] Gandomi AH, Yang X-S, Talatahari S, Alavi AH. Metaheuristic Applications in Structures and Infrastructures. First edit. London: Elsevier; 2013. http://dx.doi.org/10.1016/B978-0-12-398364-0.00001-2.

[2] Fister IJr, Yang XS, Fister I, Brest J, Fister D. A brief review of nature-inspired algorithms for optimization. Elektrotehniski Vestnik 2013;80:1-7.

[3] Rajeev S, Krishnamoorthy CS. Discrete optimization of structures using Genetic Algorithms. J Constr Eng Manag 1992;118:1233-50.

[4] Coello CA, Christiansen AD, Santos F. A simple genetic algorithm for the design of reinforced concrete beams. Eng Comput 1997;13:185-96. http://dx.doi.org/10.1007/BF01200046.

[5] Sarma KC, Adeli H. Cost Optimization of Concrete Structures. J Struct Eng 1998;124:570-8. doi:10.1061/(ASCE)0733-9445(1998)124:5(570).

[6] Alberdi R, Khandelwal K. Comparison of robustness of metaheuristic algorithms for steel frame optimization. Eng Struct 2015;102:40-60. http://dx.doi.org/10.1016/j.engstruct.2015.08.012.

[7] Toğan V. Design of planar steel frames using Teaching-Learning Based Optimization. Eng Struct 2012;34:225-32. http://dx.doi.org/10.1016/j.engstruct.2011.08.035.

[8] Bekdaş G, Nigdeli SM, Yang X. Sizing optimization of truss structures using flower pollination algorithm. Appl Soft Comput 2015;37:322-31. http://dx.doi.org/10.1016/j.asoc.2015.08.037.

[9] Talatahari S., Gandomi AH, Yang X, Deb S. Optimum design of frame structures using the Eagle Strategy with Differential Evolution. Eng Struct 2015;91:16-25. http://dx.doi.org/10.1016/j.engstruct.2015.02.026.

[10] Kripka M, de Medeiros GF, Lemonge CC. Use of optimization for automatic grouping of beam cross-section dimensions in reinforced concrete building structures. Eng Struct 2015;99:311-8. http://dx.doi.org/10.1016/j.engstruct.2013.05.012.

[11] Carbonell A, González-Vidosa F, Yepes V. Design of reinforced concrete road vaults by heuristic optimization. Adv Eng Softw 2011;42:151-9. http://dx.doi.org/10.1016/j.advengsoft.2011.01.002.

[12] Martí J V., Gonzalez-Vidosa F, Yepes V, Alcalá J. Design of prestressed concrete precast road bridges with hybrid simulated annealing. Eng Struct 2013;48:342-52. http://dx.doi.org/10.1016/j.engstruct.2012.09.014.

[13] Yepes V, Martí J V., García-Segura T. Cost and CO2 emission optimization of precast-prestressed concrete U-beam road bridges by a hybrid glowworm swarm algorithm. Autom Constr 2015;49:123-34. http://dx.doi.org/10.1016/j.autcon.2014.10.013.

[14] de Medeiros GF, Kripka M. Optimization of reinforced concrete columns according to different environmental $\begin{array}{lllll}\text { impact } & \text { assessment } & \text { parameters. 2014;59:185-94. }\end{array}$ http://dx.doi.org/10.1016/j.engstruct.2013.10.045.

[15] Camp CV., Assadollahi A. CO2 and cost optimization of reinforced concrete footings using a hybrid big bang- 
big crunch algorithm. Struct Multidiscip Optim 2013;48:411-26. http://dx.doi.org/10.1007/s00158-013-08976.

[16] Luz A., Yepes V, González-Vidosa F, Martí JV. Design of open reinforced concrete abutments road bridges with hybrid stochastic hill climbing algorithms. Inf Constr 2015;67:e114. http://dx.doi.org/10.3989/ic.14.089.

[17] García-Segura T, Yepes V, Alcalá J, Pérez-López E. Hybrid harmony search for sustainable design of posttensioned concrete box-girder pedestrian bridges. Eng Struct 2015;92:112-22. http://dx.doi.org/10.1016/j.engstruct.2015.03.015.

[18] Yepes V, García-Segura T, Moreno-Jiménez JM. A cognitive approach for the multi-objective optimization of RC structural problems. Arch Civil Mech Eng 2015;15:1024-36. http://dx.doi.org/10.1016/j.acme.2015.05.001.

[19] García-Segura T, Yepes V. Multiobjective optimization of post-tensioned concrete box-girder road bridges considering cost, CO2 emissions, and safety. Eng Struct 2016;125:325-36. http://dx.doi.org/10.1016/j.engstruct.2016.07.012.

[20] Yepes V, Alcala J, Perea C, González-Vidosa F. A parametric study of optimum earth-retaining walls by simulated annealing. Eng Struct 2008;30:821-30. http://dx.doi.org/10.1016/j.engstruct.2007.05.023.

[21] Yepes V, Gonzalez-Vidosa F, Alcala J, Villalba P. CO2-Optimization Design of Reinforced Concrete Retaining Walls Based on a VNS-Threshold Acceptance Strategy. J Comput Civ Eng 2012;26:378-86. http://dx.doi.org/10.1061/(ASCE)CP.1943-5487.0000140.

[22] Talatahari S, Sheikholeslami R. Optimum design of gravity and reinforced retaining walls using enhanced charged system search algorithm. KSCE J Civ Eng 2014;18:1464-9. http://dx.doi.org/10.1007/s12205-0140406-5.

[23] Sheikholeslami R, Khalili BG, Zahrai SM. Optimum Cost Design of Reinforced Concrete Retaining Walls Using Hybrid Firefly Algorithm. Int J Eng Technol 2014;6:465-70.

[24] Gandomi AH, Kashani AR, Roke DA, Mousavi M. Optimization of retaining wall design using recent swarm intelligence techniques. Eng Struct 2015;103:72-84. http://dx.doi.org/10.1016/j.engstruct.2015.08.034.

[25] Bekdaş G. Harmony Search Algorithm Approach for Optimum Design of Post-Tensioned Axially Symmetric Cylindrical Reinforced Concrete Walls. J Optim Theory Appl 2015;164:342-58.

[26] Khajehzadeh M, Taha MR, El-Shafie A, Eslami M. A modified gravitational search algorithm for slope stability analysis. Eng Appl Artif Intell 2012;25:1589-97. http://dx.doi.org/10.1016/j.engappai.2012.01.011.

[27] Zastrow P, Molina-Moreno F, García-Segura T, Martí JV, Yepes V. Life cycle assessment of cost-optimized buttress earth-retaining walls: a parametric study. J Clean Prod 2017;140:1037-48. http://dx.doi.org/10.0.3.248/j.jclepro.2016.10.085.

[28] Fomento M. Collection of earth retaining structures for roads. Madrid: Fomento M.; 1989.

[29] Fomento M. EHE: Code of structural concrete. Madrid: Fomento M.; 2008.

[30] Huntington WC. Earth Pressures and Retaining Wall. New York: John Wiley and Sons; 1957.

[31] Rankine WJ. On the stability of loose earth. Philos Trans R Soc London 1857;147:9-27.

[32] CEB-FIB Model Code. Design code. London: Thomas Telford Services Ltd.; 1990.

[33] Calavera J. Muros de contención y muros de sótano [in Spanish]. Madrid: Intemac; 2001.

[34] Geem ZW, Kim JH, Loganathan G V. A new heuristic optimization algorithm: Harmony search. Simulation 2001;76:60-8.

[35] Alia OM, Mandava R. The variants of the harmony search algorithm: an overview. Artif Intell Rev 2011;36:49-68. http://dx.doi.org/10.1007/s10462-010-9201-y.

[36] Guo Z, Yang H, Wang S, Zhou C, Liu X. Adaptive harmony search with best-based search strategy. Soft Comput 2016;1-15. http://dx.doi.org/10.1007/s00500-016-2424-3.

[37] Manjarres D, Landa-Torres I, Gil-Lopez S, Del Ser J, Bilbao MN, Salcedo-Sanz S, Geem ZW. A survey on applications of the harmony search algorithm. Eng Appl Artif Intell 2013;26:1818-31. http://dx.doi.org/10.1016/j.engappai.2013.05.008. 
[38] Saka MP, Hasançebi O, Geem ZW. Metaheuristics in structural optimization and discussions on harmony search algorithm. Swarm Evol Comput 2016;28:88-97. http://dx.doi.org/10.1016/j.swevo.2016.01.005.

[39] Dueck G, Scheuer T. Threshold Accepting: A general Purpose Optimization Algorithm appearing Superior to Simulated Annealing. J Comput Phys 1990;90:161-75.

[40] Payá-Zaforteza I, Yepes V, González-Vidosa F, Hospitaler A. On the Weibull cost estimation of building frames designed by simulated annealing. Meccanica 2010;45:693-704. 
Table 1. Unit costs

\begin{tabular}{ll}
\hline Unit & Cost $(\boldsymbol{€})$ \\
\hline $\mathrm{m}^{3}$ of concrete HA-25 in stem & 56.66 \\
\hline $\mathrm{m}^{3}$ of concrete HA-30 in stem & 60.80 \\
\hline $\mathrm{m}^{3}$ of concrete HA-35 in stem & 65.32 \\
\hline $\mathrm{m}^{3}$ of concrete HA-40 in stem & 70.41 \\
\hline $\mathrm{m}^{3}$ of concrete HA-45 in stem & 75.22 \\
\hline $\mathrm{m}^{3}$ of concrete HA-50 in stem & 80.03 \\
\hline $\mathrm{m}^{3}$ of concrete HA-25 in foundation & 50.65 \\
\hline $\mathrm{m}^{3}$ of concrete HA-30 in foundation & 54.79 \\
\hline $\mathrm{m}^{3}$ of concrete HA-35 in foundation & 59.31 \\
\hline $\mathrm{m}^{3}$ of concrete HA-40 in foundation & 64.40 \\
\hline $\mathrm{m}^{3}$ of concrete HA-45 in foundation & 69.21 \\
\hline $\mathrm{m}^{3}$ of concrete HA-50 in foundation & 74.02 \\
\hline $\mathrm{kg}$ of steel B400S & 0.56 \\
\hline $\mathrm{kg}$ of steel B500S & 0.58 \\
\hline $\mathrm{m}^{3}$ stem formwork & 21.61 \\
\hline $\mathrm{m}^{2}$ of foundation formwork & 18.03 \\
\hline $\mathrm{m}^{2}$ of earth removal & 3.01 \\
\hline $\mathrm{m}^{3}$ front in-fill & 4.81 \\
\hline $\mathrm{m}^{3}$ of backfill & 5.56 \\
\hline
\end{tabular}

Table 2. Design variables

\begin{tabular}{|c|c|c|c|c|c|}
\hline Variables & & Lower Bound & Increment & $\begin{array}{l}\text { Upper bound } \\
\text { (cm) }\end{array}$ & $\begin{array}{l}\mathrm{N}^{\circ} \text { of } \\
\text { values }\end{array}$ \\
\hline$c$ & & $H / 20$ & $5 \mathrm{~cm}$ & $\mathrm{H} / 5$ & $\mathrm{f}(H)^{*}$ \\
\hline$b$ & & $25 \mathrm{~cm}$ & $2.5 \mathrm{~cm}$ & 122.5 & 40 \\
\hline$p$ & & $20 \mathrm{~cm}$ & $10 \mathrm{~cm}$ & 610 & 60 \\
\hline$t$ & & $20 \mathrm{~cm}$ & $15 \mathrm{~cm}$ & 905 & 60 \\
\hline$e_{c}$ & & $25 \mathrm{~cm}$ & $2.5 \mathrm{~cm}$ & 122.5 & 40 \\
\hline$d$ & & $\mathrm{H} / 5 \mathrm{~cm}$ & $5 \mathrm{~cm}$ & $2 \mathrm{H} / 3$ & $\mathrm{f}(H)^{*}$ \\
\hline$f_{c k}$ & & $25,20,25,40,45,50$ & & & 7 \\
\hline$f_{y k}$ & & 400,500 & & & 2 \\
\hline \multirow[t]{2}{*}{$A_{1}$ to $A_{10}$} & $\varnothing$ & $\begin{array}{c}6,8,10,12,16,20 \\
25,32\end{array}$ & & & 8 \\
\hline & $n$ & 1 steel rebar & 2 rebars & 12 rebars & 6 \\
\hline \multirow[t]{2}{*}{$A_{11}$ to $A_{12}$} & $\varnothing$ & $\begin{array}{c}6,8,10,12,16,20 \\
25,32\end{array}$ & & & 8 \\
\hline & $n$ & 1 steel rebar & 4 rebars & 10 rebars & 7 \\
\hline
\end{tabular}

*Number of values depends on the height

Table 3. Types of fill considered (density and internal friction angles)

\begin{tabular}{|c|c|c|c|}
\hline Type of fill & Description & $\begin{array}{c}\text { Density } \gamma \\
\left(\mathbf{k N} / \mathbf{m}^{3}\right)\end{array}$ & $\begin{array}{l}\text { Internal friction } \\
\text { angle } \phi\left({ }^{\circ}\right)\end{array}$ \\
\hline$F_{1}$ & Coarse granular fill $(\mathrm{GW}, \mathrm{GP})$ & 22 & 35 \\
\hline$F_{2}$ & $\begin{array}{l}\text { Granular soils with more than } 12 \% \text { fines (GW, GS, SM, SL) and fine } \\
\text { soils with more than } 25 \% \text { coarse grains (CL-ML) }\end{array}$ & 20 & 30 \\
\hline$F_{3}$ & $\begin{array}{l}\text { Fine soils of low plasticity with less than } 25 \% \text { coarse grains (CL- } \\
\text { ML) }\end{array}$ & 18 & 24 \\
\hline
\end{tabular}


Table 4. Calibration of HSTA parameters

\begin{tabular}{cccccccc}
\hline HMS & n HMS & HMCR & HMP & PAR & TI & Par $_{\text {var }}$ & IWI \\
\hline 30 & 3 & 0.6 & 0.6 & 0.2 & 200 & 0.1 & 50 \\
\hline 50 & 4 & 0.7 & 0.7 & 0.4 & 500 & 0.2 & 100 \\
\hline 100 & 5 & 0.8 & 0.75 & & 1000 & 0.3 & 150 \\
\hline 200 & & 0.85 & 0.8 & & 5000 & 0.4 & 200 \\
\hline 300 & & 0.9 & 0.9 & & & 0.5 & 300 \\
\hline
\end{tabular}

Table 5. Best performing results

\begin{tabular}{ccccccccccc}
\hline HMS & $\mathbf{n}_{\text {HMS }}$ & HMCR & HMP & PAR & TI & Pvar & IWI & Cost reduction in TA & Average( $(\mathbf{)})$ & $\begin{array}{c}\text { Standard } \\
\text { Deviation (€) }\end{array}$ \\
\hline 200 & 4 & 0.8 & 0.1 & 0.2 & 1000 & 0.3 & 150 & $5 \%$ & 1096.93 & 11.43 \\
\hline 300 & 4 & 0.85 & 0.9 & 0.2 & 5000 & 0.1 & 500 & $5 \%$ & 1080.91 & 14.97 \\
\hline 300 & 4 & 0.85 & 0.2 & 0.2 & 1000 & 0.1 & 500 & $1 \%$ & 1083.30 & 19.75 \\
\hline 200 & 4 & 0.7 & 0.6 & 0.2 & 5000 & 0.4 & 300 & $1 \%$ & 1063.80 & 8.47 \\
\hline 200 & 4 & 0.8 & 0.9 & 0.2 & 1000 & 0.3 & 300 & $1 \%$ & 1094.88 & 8.34 \\
\hline
\end{tabular}

Table 6. Fixed parameters for the design parametric study

\begin{tabular}{ll}
\hline Design parameters & Value \\
\hline Fill slope, $\beta$ & 0 \\
Foundation depth, $H_{2}$ & $2 \mathrm{~m}$ \\
Uniform load on top of the fill, $\gamma$ & $10 \mathrm{kN} / \mathrm{m}^{2}$ \\
Wall-fill friction angle, $\delta$ & $0^{\circ}$ \\
Base-friction coefficient, $\mu$ & $\operatorname{tg~} 30^{\circ}$ \\
Safety coefficient against sliding, $\gamma_{f s}$ & 1.5 \\
Safety coefficient against overturning, $\gamma_{f o}$ & 1.8 \\
EHE safety coefficient for loading & Normal \\
ULS safety coefficient of concrete & 1.5 \\
ULS safety coefficient of steel & 1.15 \\
EHE ambient exposure & IIa \\
\hline
\end{tabular}

Table 7. Comparison of results for $\mathrm{H}=7$ and fill $F_{1}$

\begin{tabular}{llll}
\hline & \multicolumn{3}{c}{ Maximum bearing pressure } \\
\cline { 2 - 4 } & $0.2 \mathrm{MPa}$ & $0.3 \mathrm{MPa}$ & $0.4 \mathrm{MPa}$ \\
\hline Average Cost $(€)$ & 667.39 & 639.23 & 650.82 \\
Best cost $(€)$ & 643.77 & 618.76 & 628.73 \\
$b(\mathrm{~m})$ & 0.25 & 0.25 & 0.25 \\
$c(\mathrm{~m})$ & 0.37 & 0.36 & 0.38 \\
$p(\mathrm{~m})$ & 0.46 & 0.2 & 0.57 \\
$t(\mathrm{~m})$ & 1.40 & 1.38 & 1.07 \\
$e_{c}(\mathrm{~m})$ & 0.25 & 0.25 & 0.63 \\
$d(\mathrm{~m})$ & 2.98 & 3.14 & 2.85 \\
$R_{\mathrm{st}}(\mathrm{kg})$ & 71.10 & 74.0 & 71.20 \\
$R_{\mathrm{ft}}(\mathrm{kg})$ & 47.60 & 27.50 & 32.50 \\
$R_{t}(\mathrm{~kg} / \mathrm{m})$ & 38.29 & 34.40 & 32.83 \\
\hline
\end{tabular}


Table 8. Cost results in fill $F_{1}$

\begin{tabular}{clllll}
\hline $\mathrm{H}(\mathrm{m})$ & $0.2 \mathrm{MPa}$ & $\begin{array}{l}\text { Difference } \\
\text { with 0.4 MPa }\end{array}$ & $\begin{array}{l}\text { 0.3 MPa } \\
\text { Difference }\end{array}$ & $\begin{array}{l}\text { Dith0.4 MPa } \\
\text { wPa }\end{array}$ \\
\hline 4 & 318.17 & $-1.14 \%$ & 322.20 & $0.13 \%$ & 321.79 \\
5 & 413.98 & $1.60 \%$ & 414.13 & $1.64 \%$ & 407.34 \\
6 & 527.38 & $0.25 \%$ & 520.32 & $-1.10 \%$ & 526.06 \\
7 & 667.40 & $2.48 \%$ & 639.23 & $-1.81 \%$ & 650.82 \\
8 & 800.11 & $0.93 \%$ & 790.92 & $-0.22 \%$ & 792.64 \\
9 & 942.23 & $1.37 \%$ & 934.14 & $0.52 \%$ & 929.30 \\
10 & $1,110.31$ & $0.20 \%$ & $1,155.78$ & $4.12 \%$ & $1,108.11$ \\
11 & $1,406.45$ & $9.44 \%$ & $1,297.39$ & $1.83 \%$ & $1,273.66$ \\
12 & $1,615.51$ & $5.38 \%$ & $1,608.24$ & $4.95 \%$ & $1,528.57$ \\
13 & $1,874.23$ & $7.96 \%$ & $1,806.85$ & $4.53 \%$ & $1,725.02$ \\
14 & $2,301.57$ & $12.29 \%$ & $2,172.99$ & $7.09 \%$ & $2,018.82$ \\
15 & $2,602.19$ & $14.07 \%$ & $2,501.85$ & $10.63 \%$ & $2,235.93$ \\
16 & $2,955.75$ & $11.76 \%$ & $2,835.09$ & $8.00 \%$ & $2,608.30$ \\
\hline
\end{tabular}

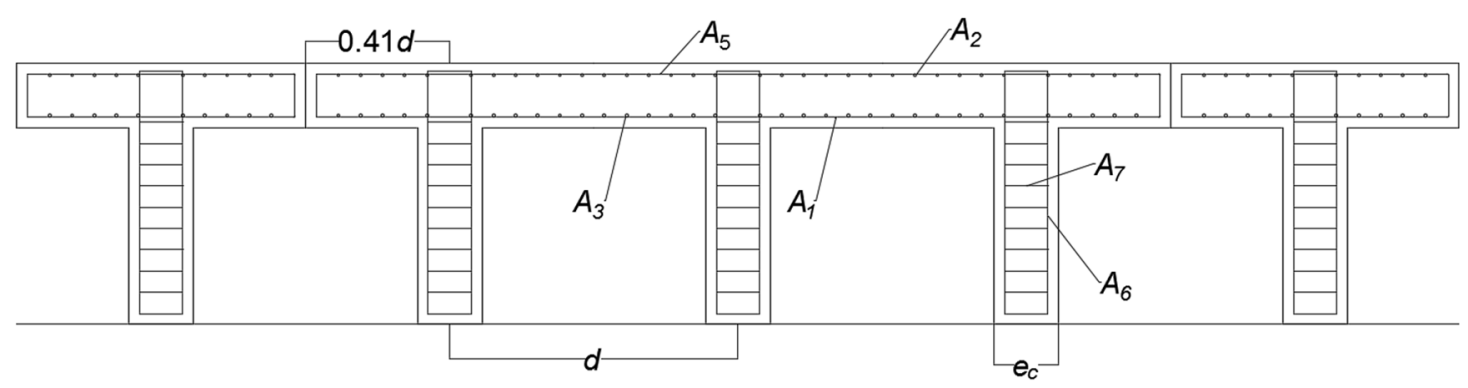

Fig. 1. Earth-retaining wall with buttresses. Floor plan 


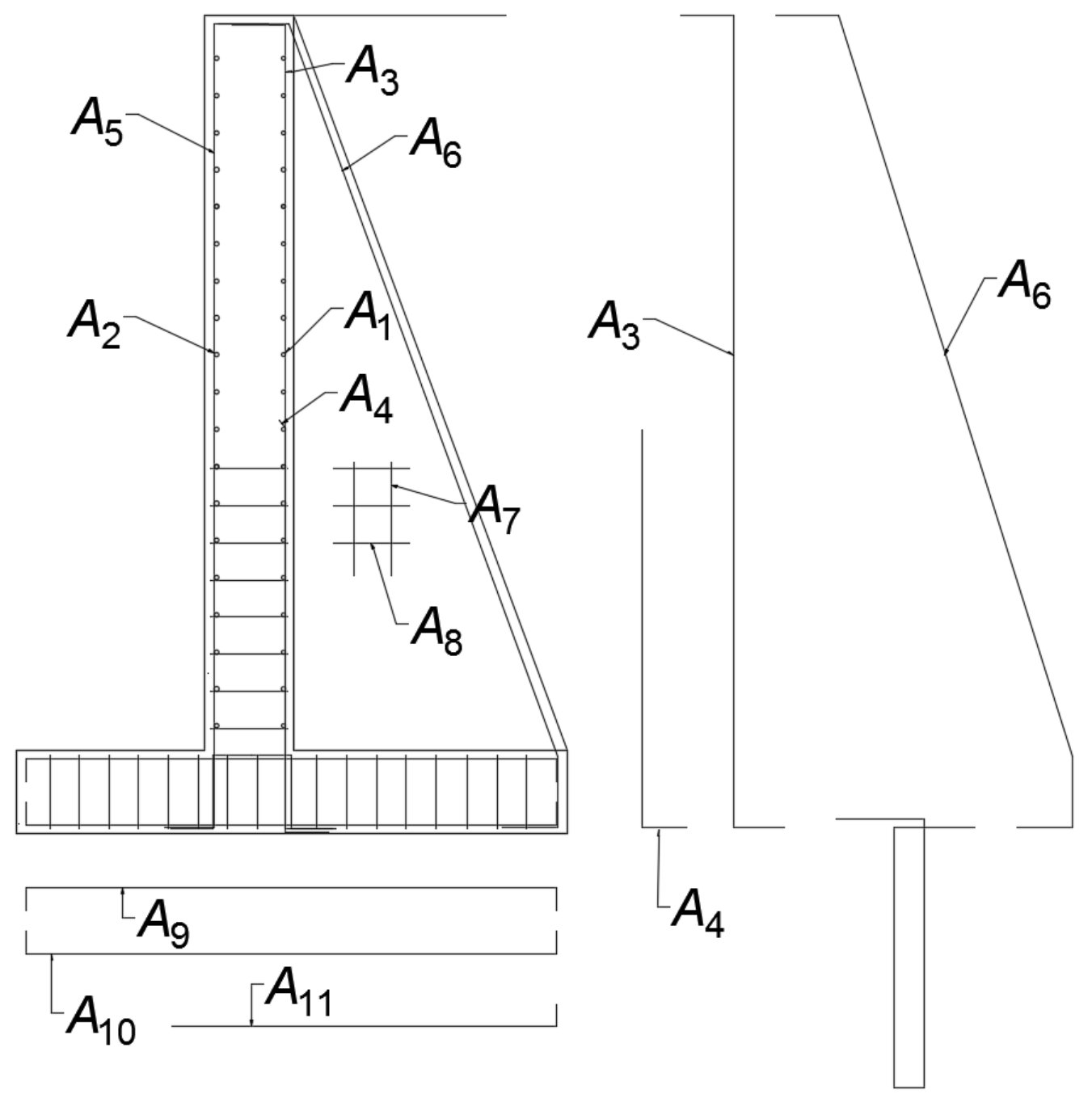

Fig. 2. Reinforcement variables for the design of earth-retaining walls. Elevation. Source: Yepes et al. (2015) 


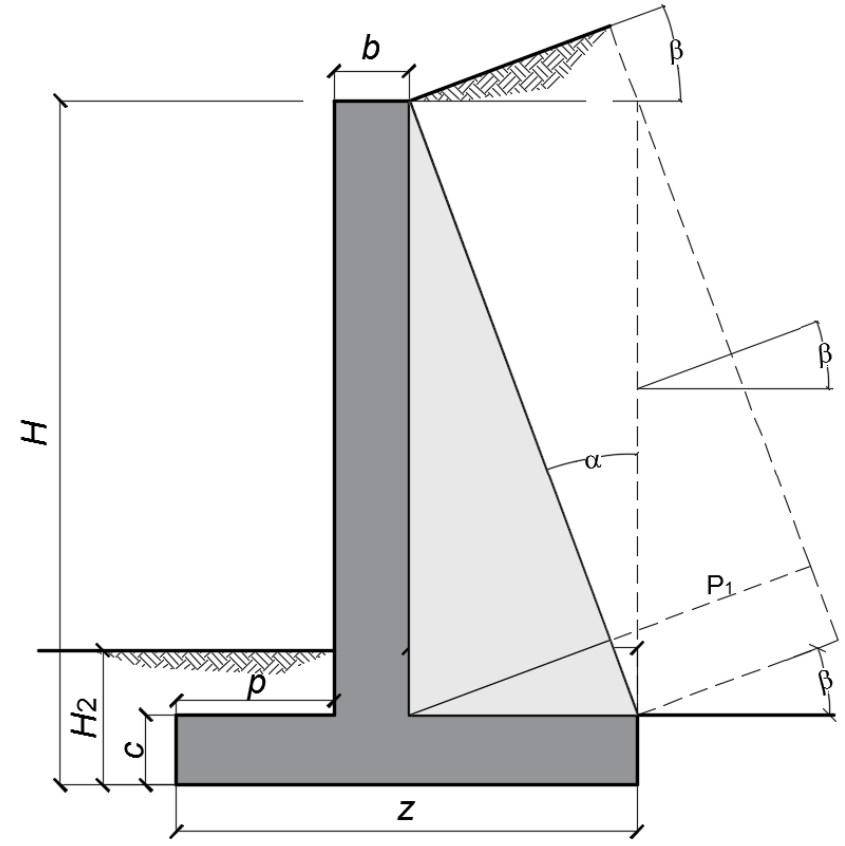

a)

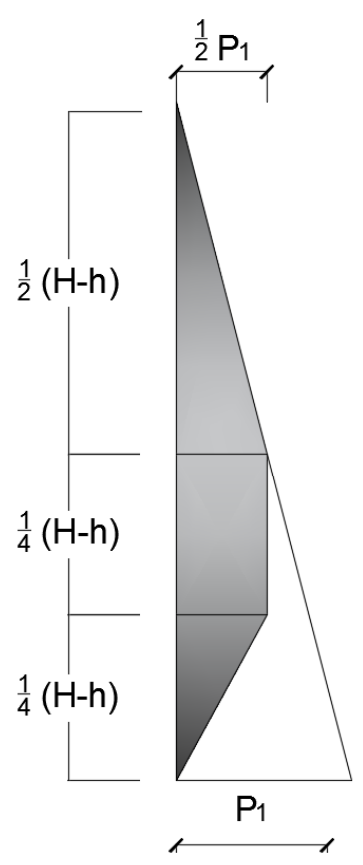

b)

Fig. 3. Dimensions of a buttressed wall

Step 1- Assignment of the algorithm parameters

Step 2- Initialization of the harmony memory

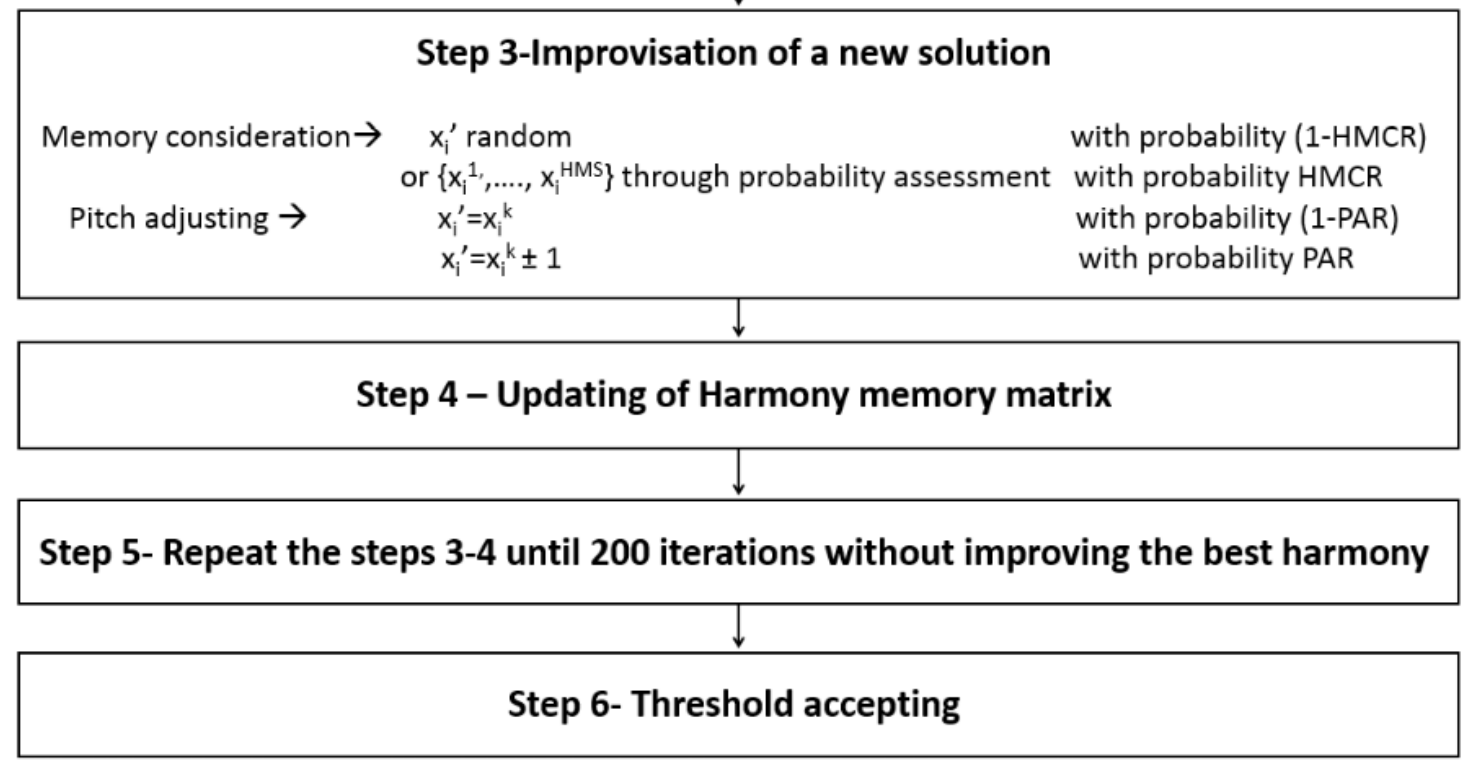

Fig. 4. HSTA flowchart 


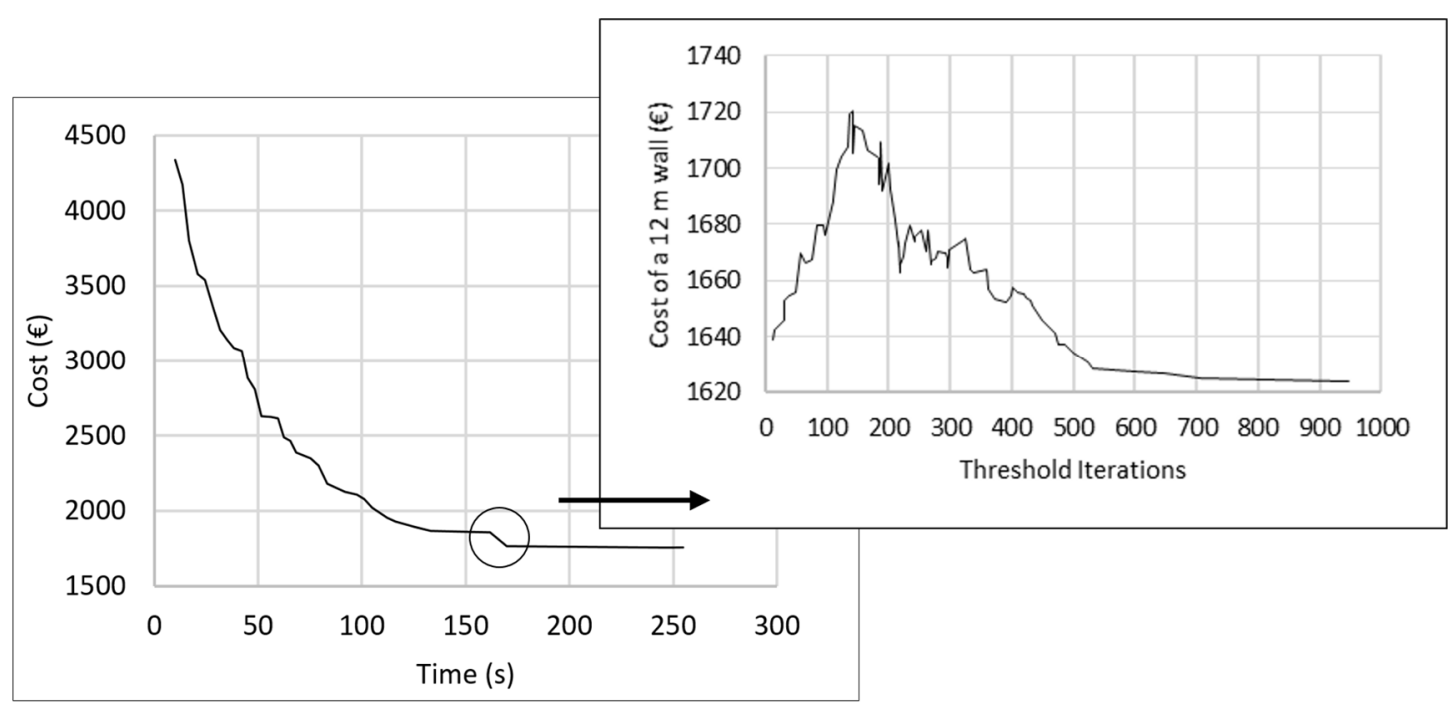

Fig. 5. Typical cost variation for hybrid harmony search (HSTA)

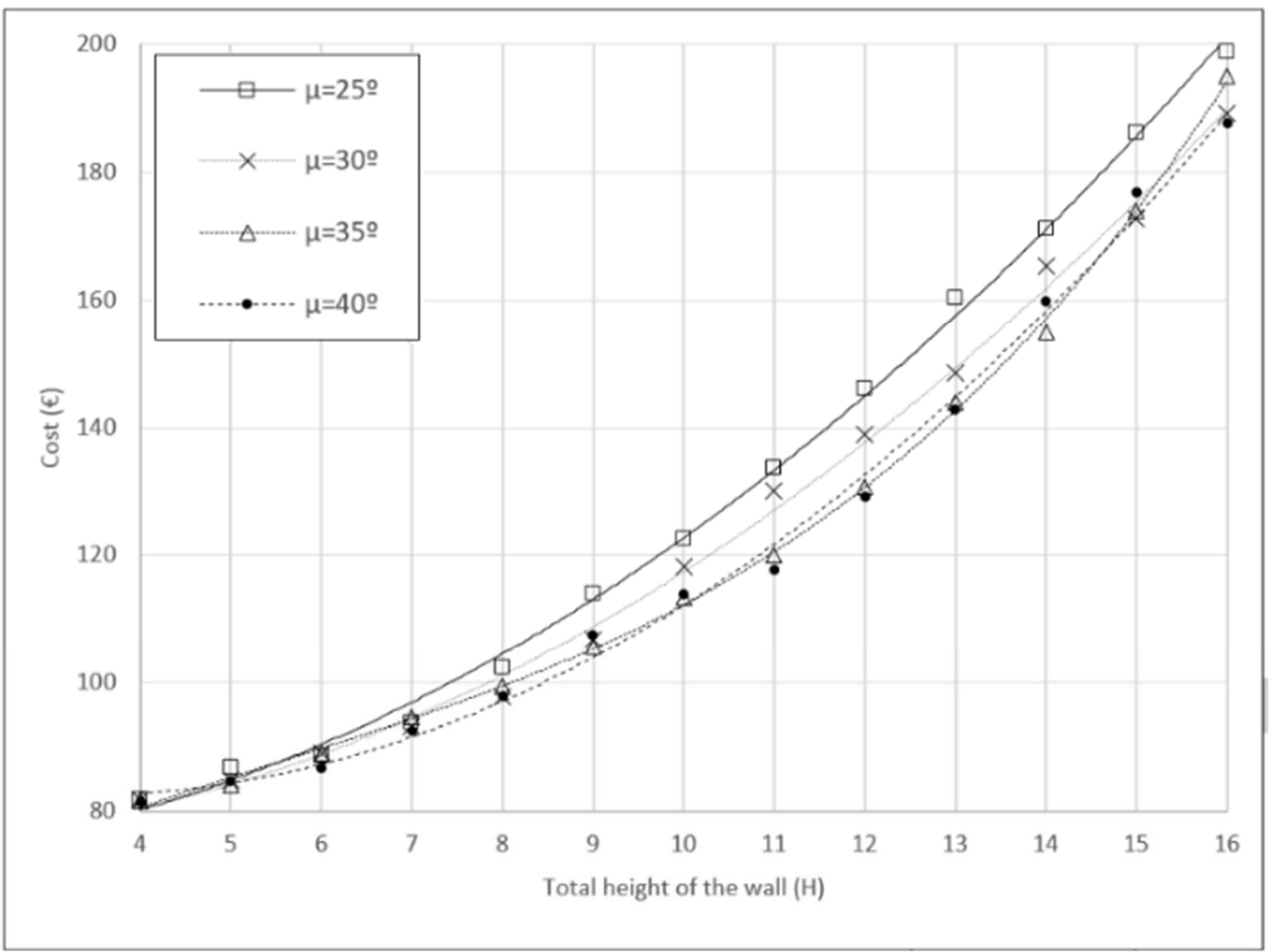

Fig. 6. Cost Variation for different base-friction angles in fill $F_{2}$ and $0.3 \mathrm{MPa}$ maximum bearing pressure 


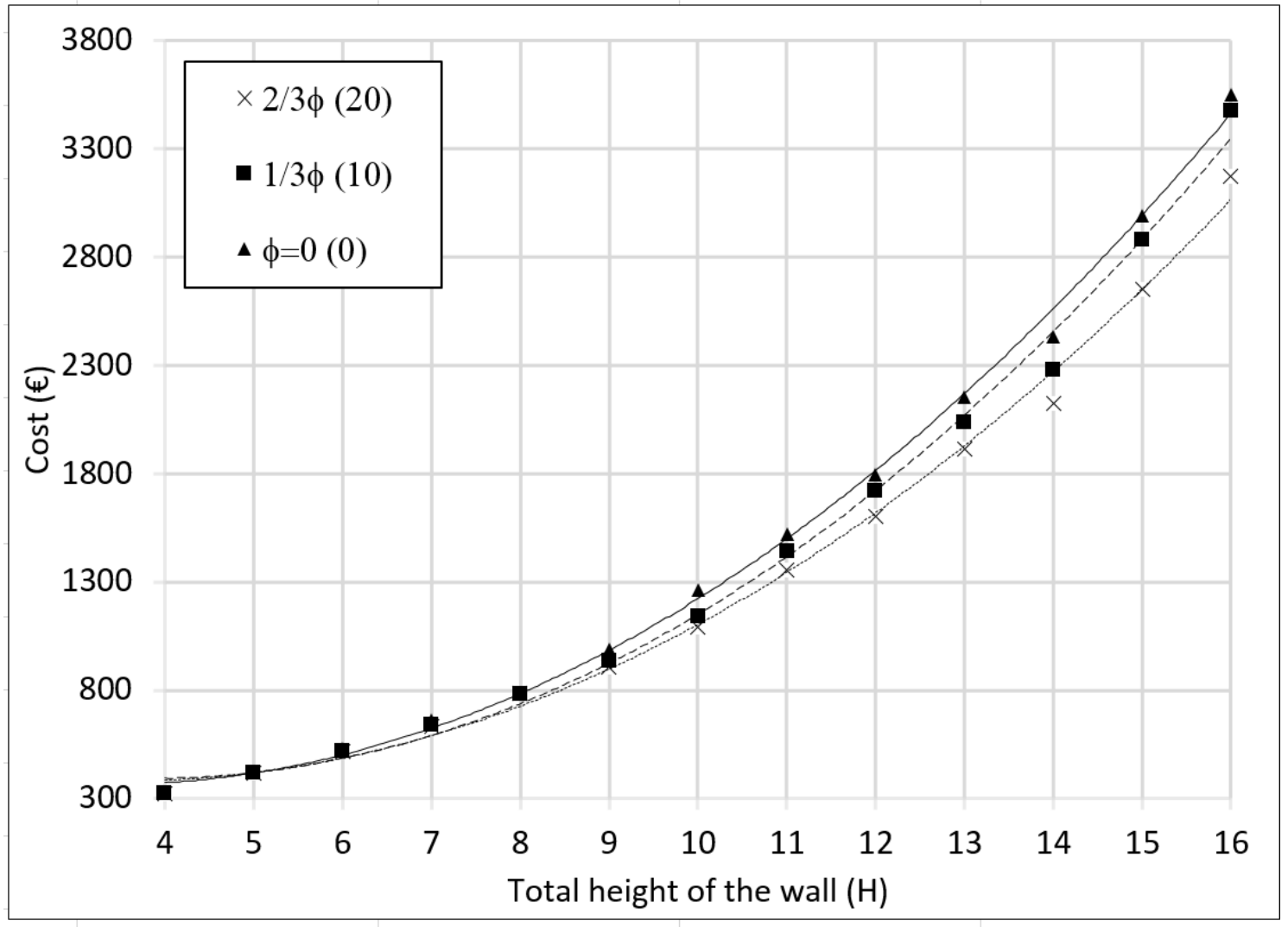

Fig. 7. Cost variation for different wall-fill friction angles. $10^{\circ}$ angle of passive pressure 


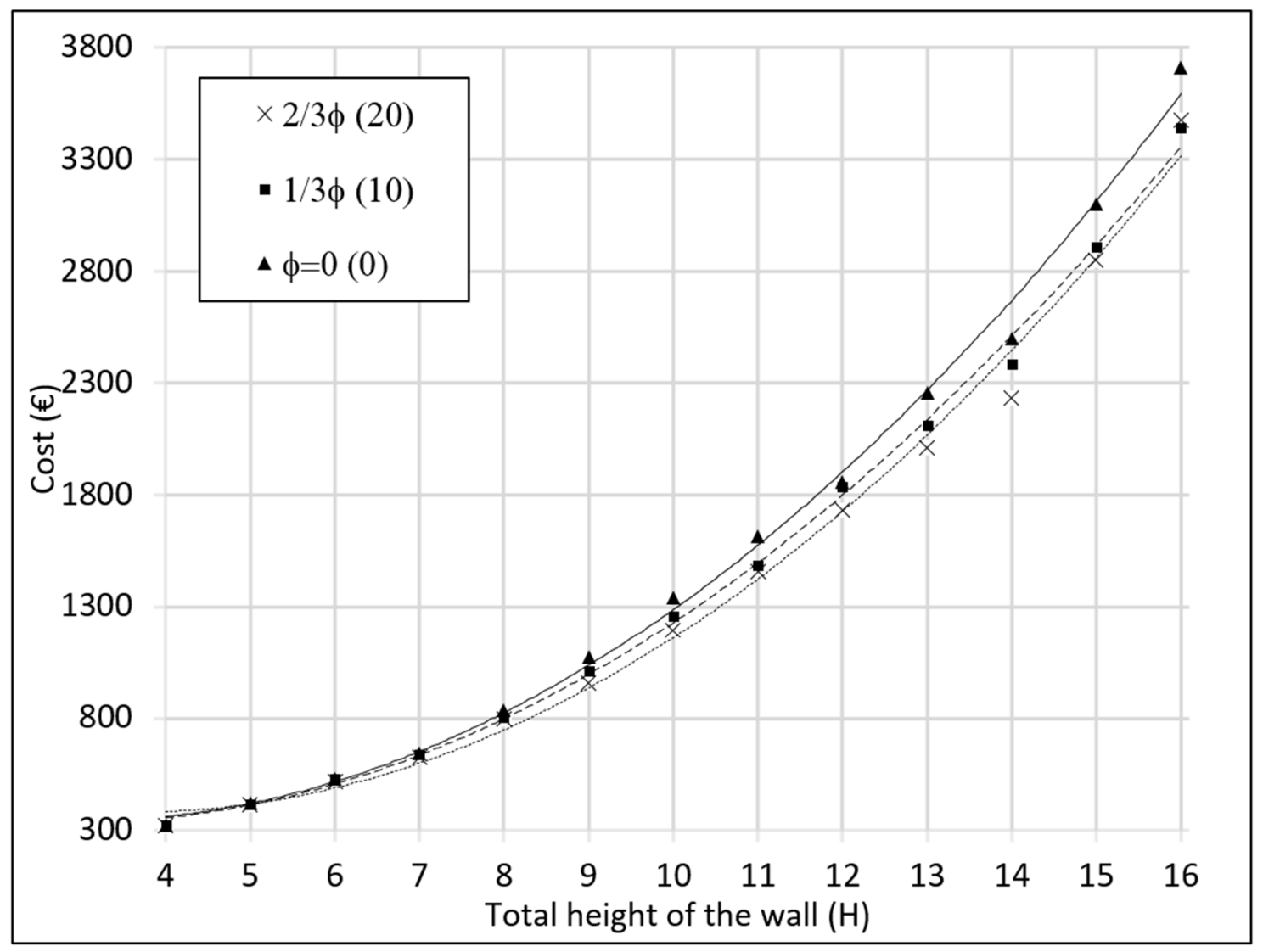

Fig. 8. Cost variation for different wall-fill friction angles. $0^{\circ}$ angle of passive pressure 


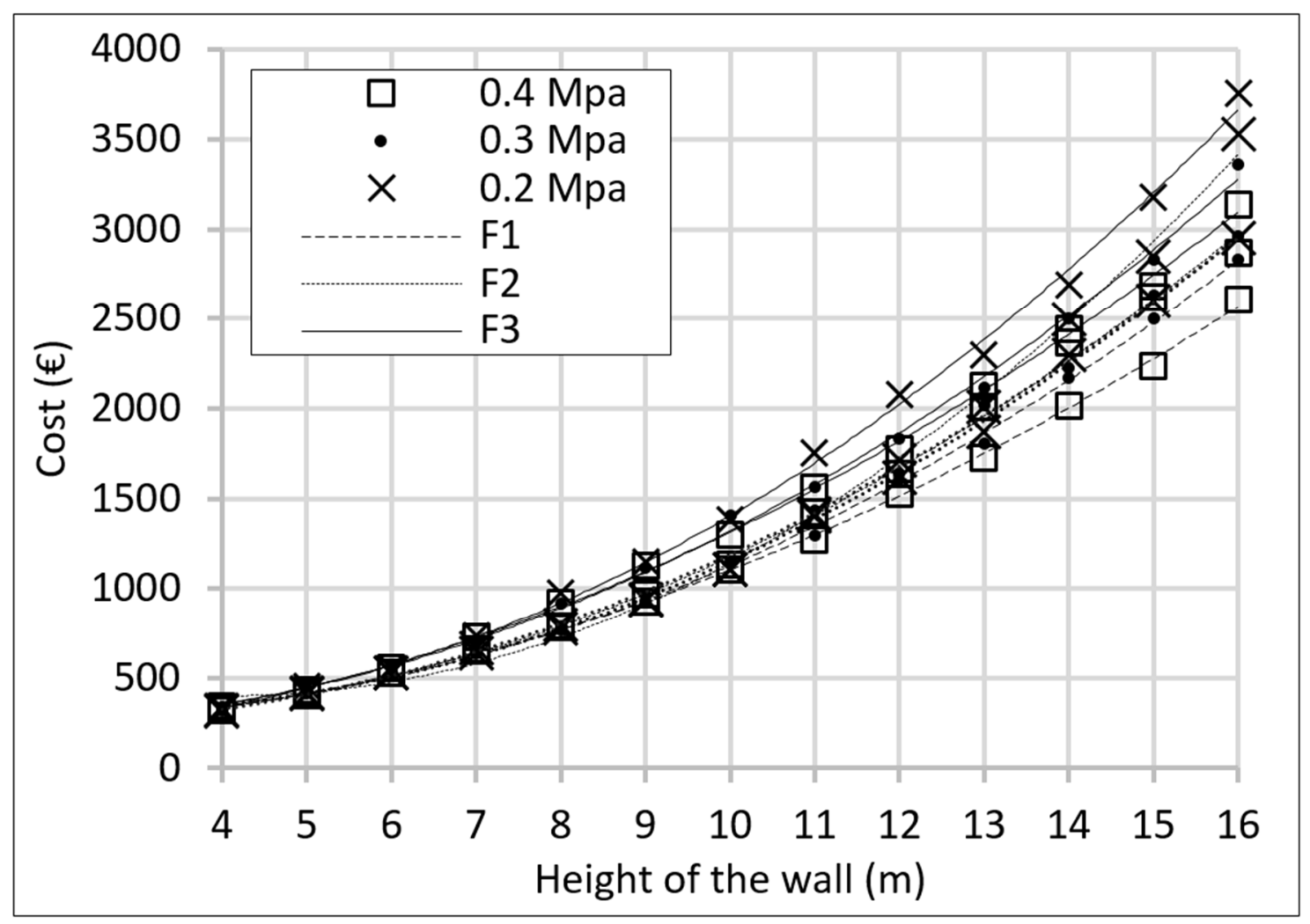

Fig. 9. Cost variation for different wall-fill friction conditions

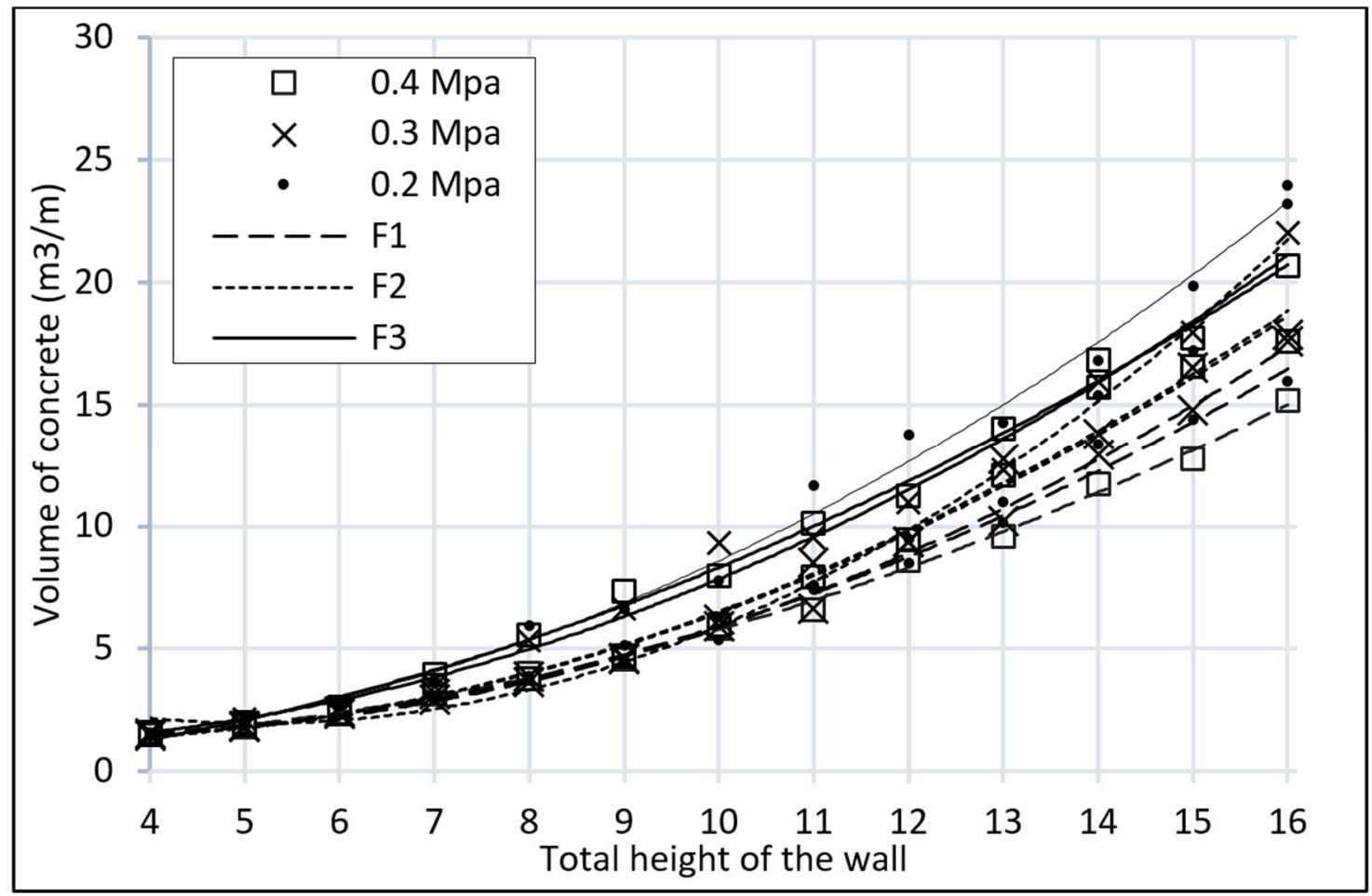

Fig. 10. Variation of volume of concrete per linear meter 


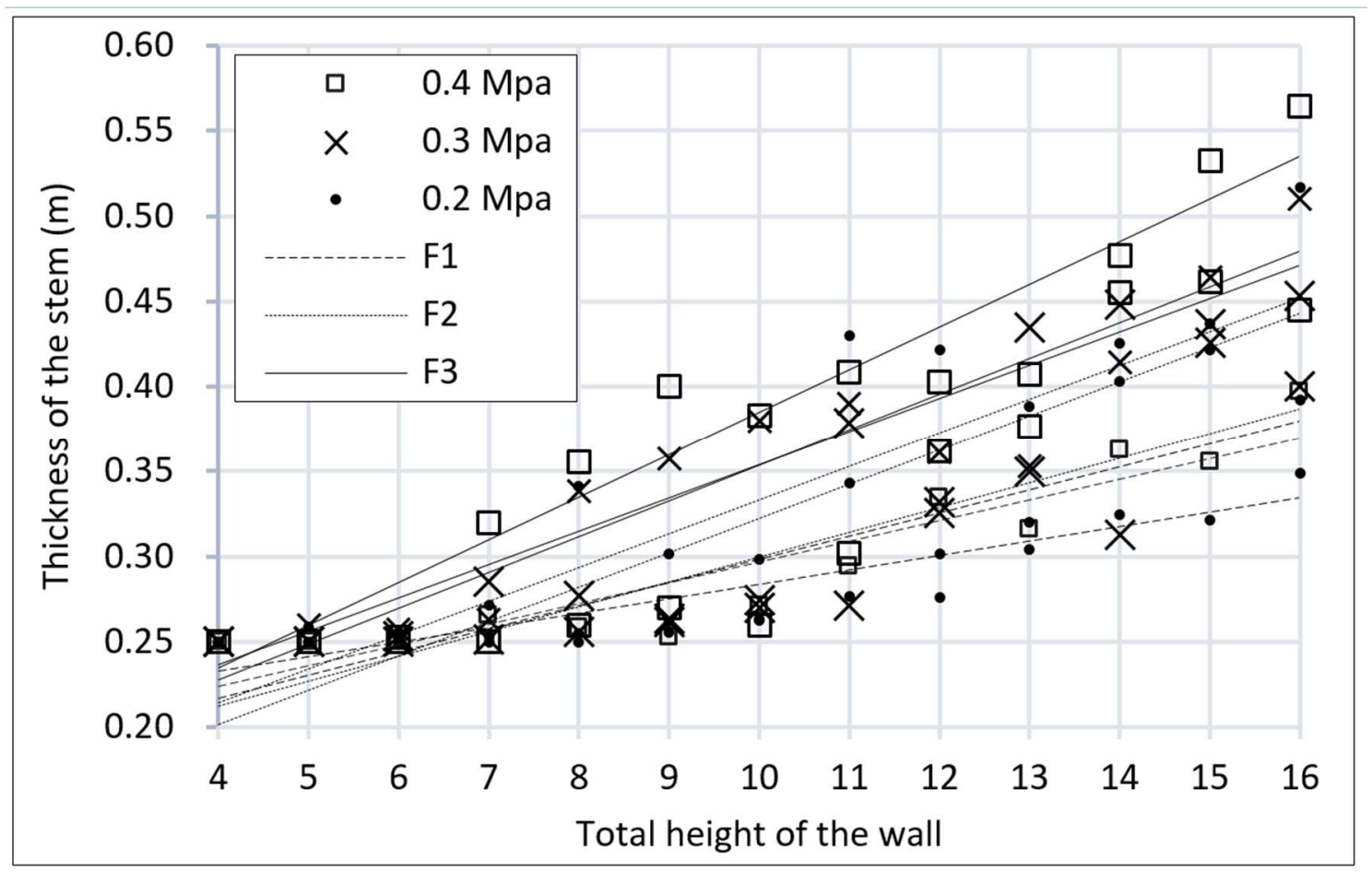

Fig. 11. Variation of thickness of the stem

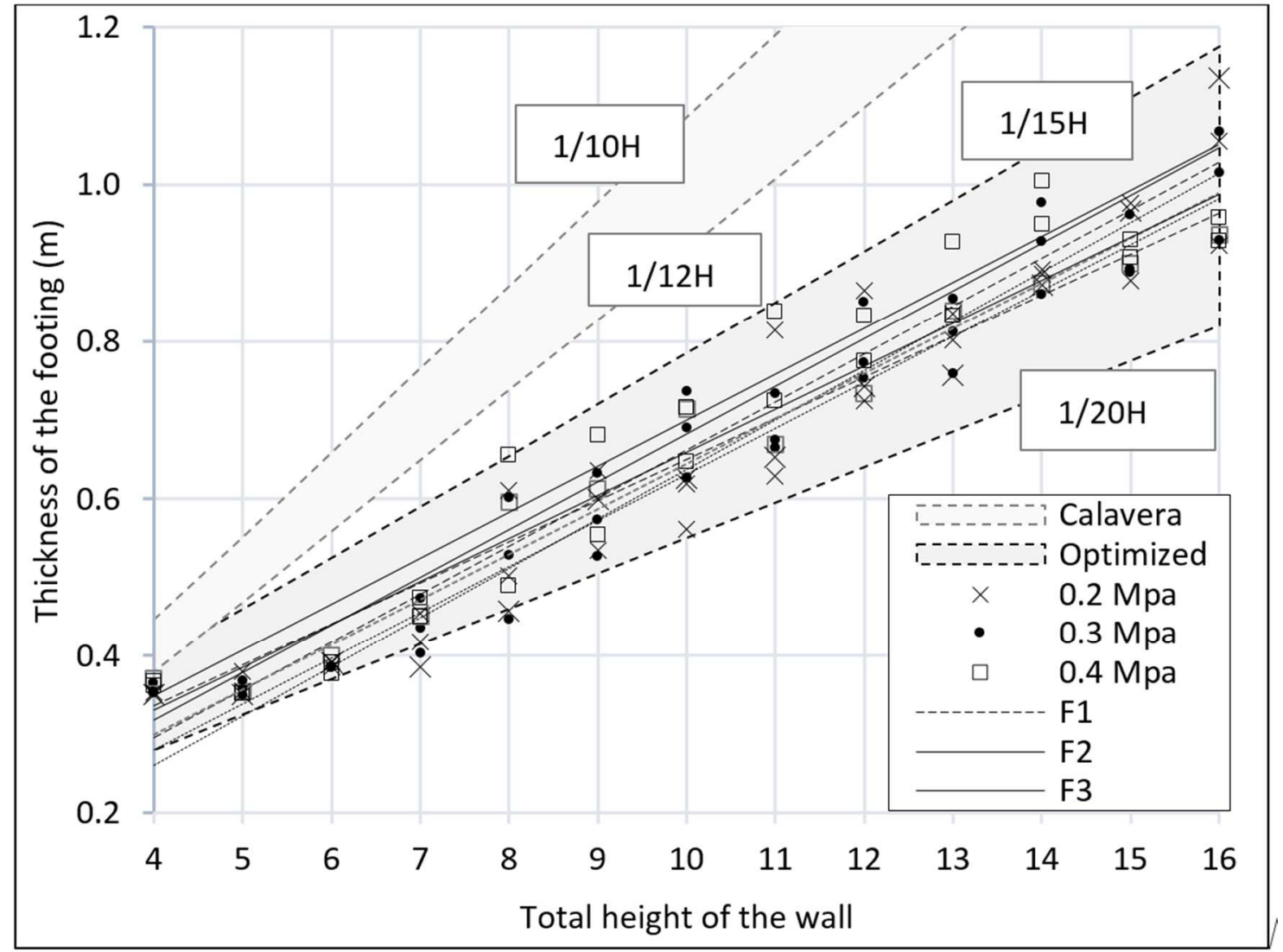

Fig. 12. Variation of thickness of the footing compared to Calavera's recommendations 


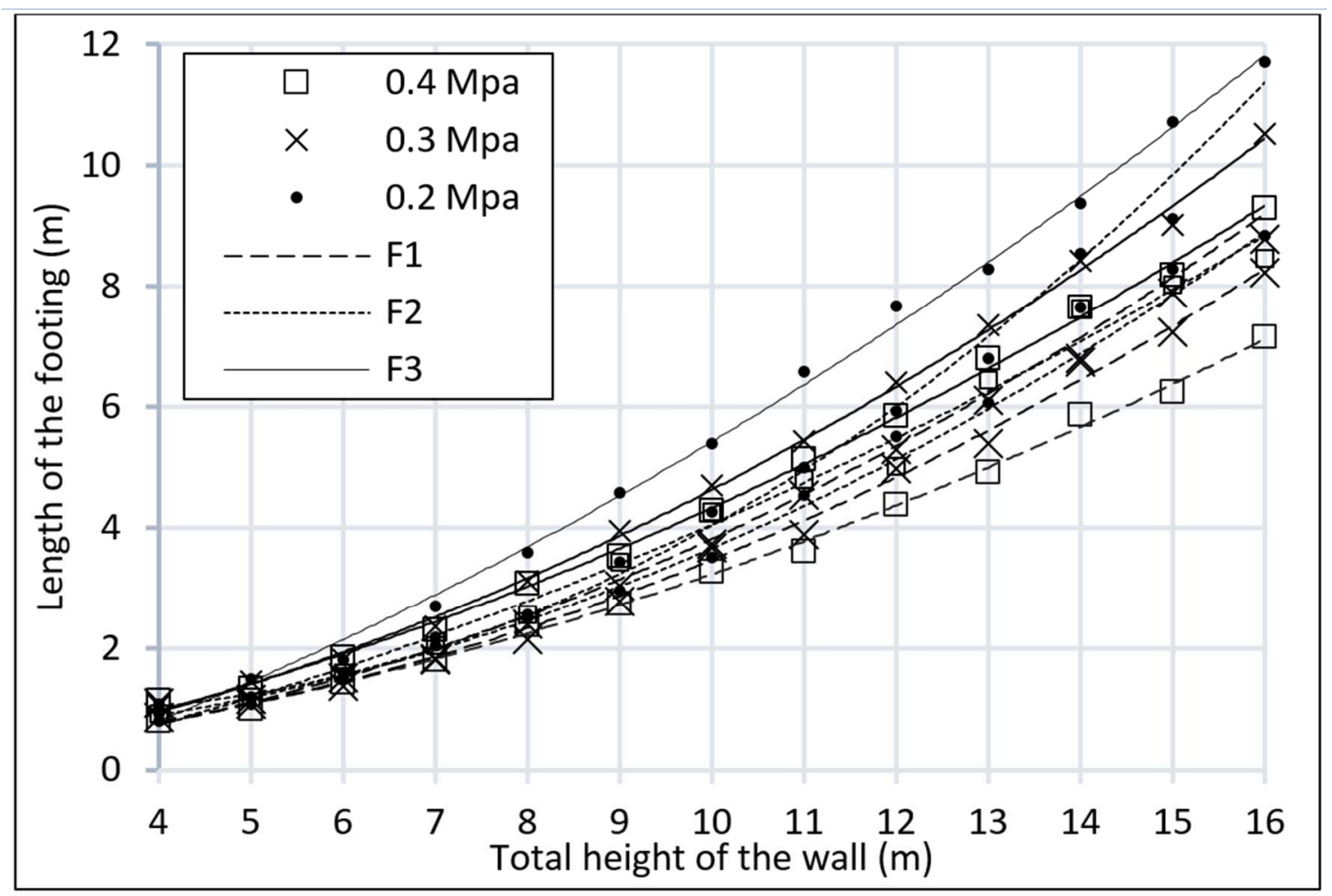

Fig. 13. Variation of length of the footing

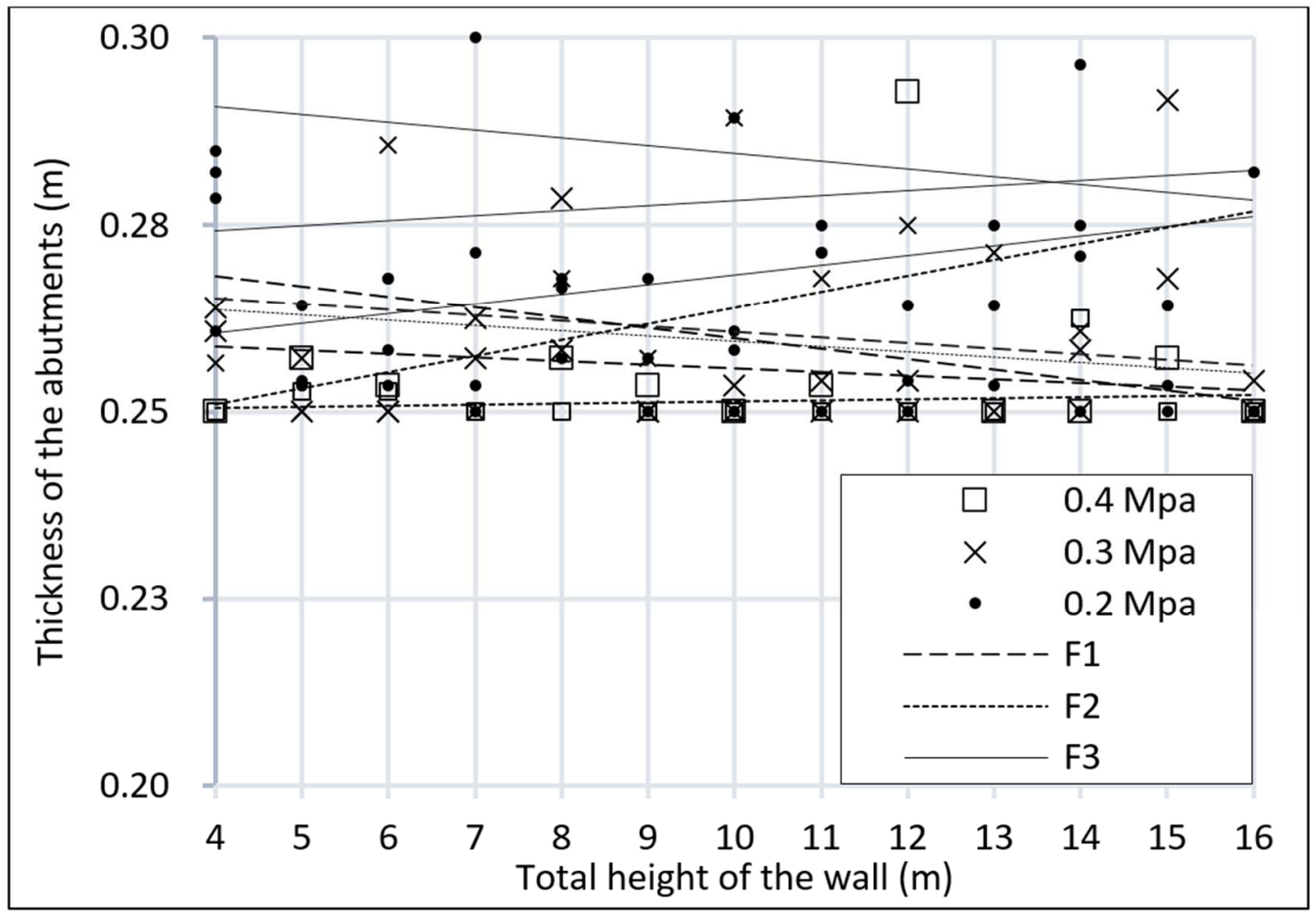

Fig. 14. Variation of thickness of the buttresses 


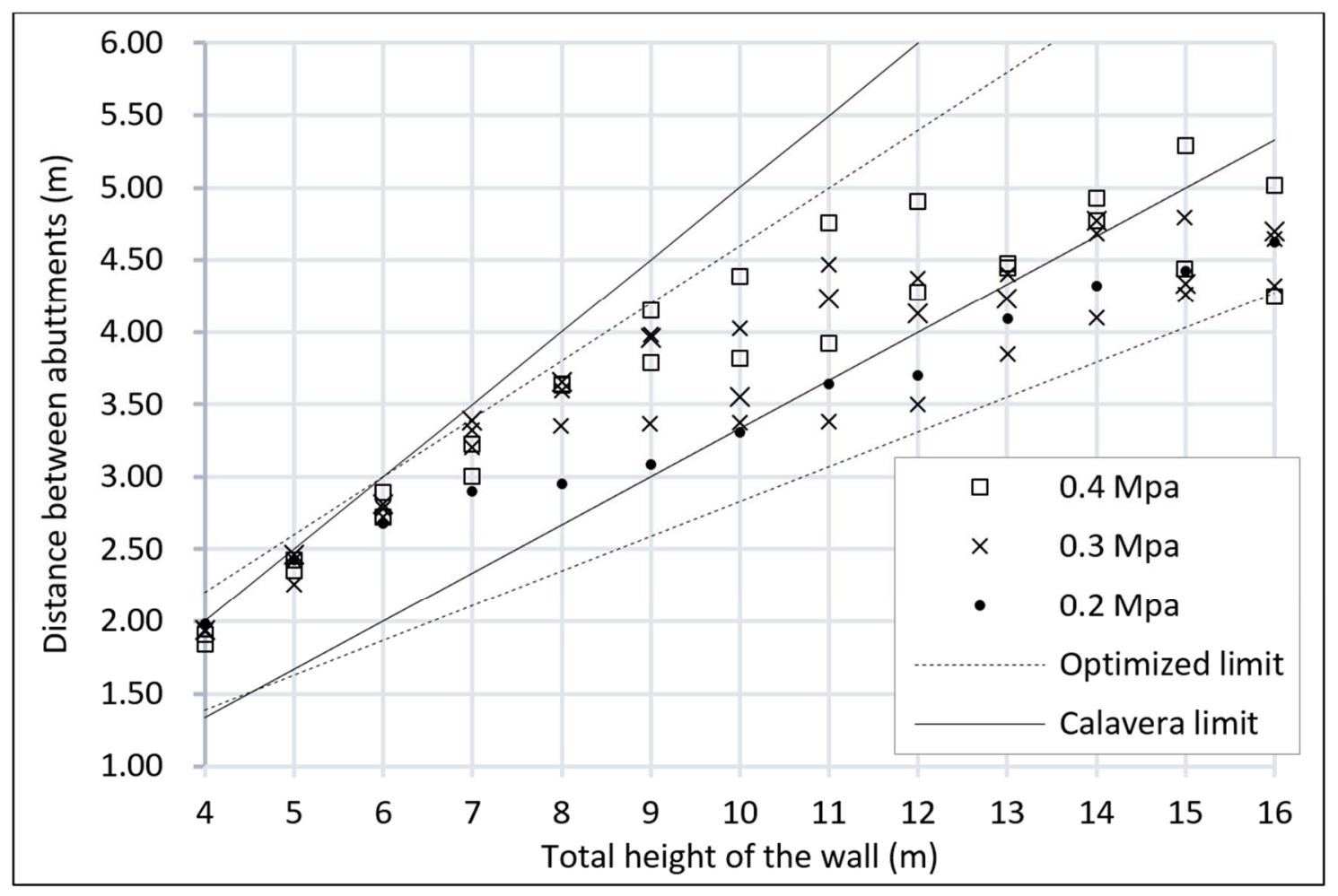

Fig. 15. Variation of the distance between buttresses, compared to Calavera's recommendations

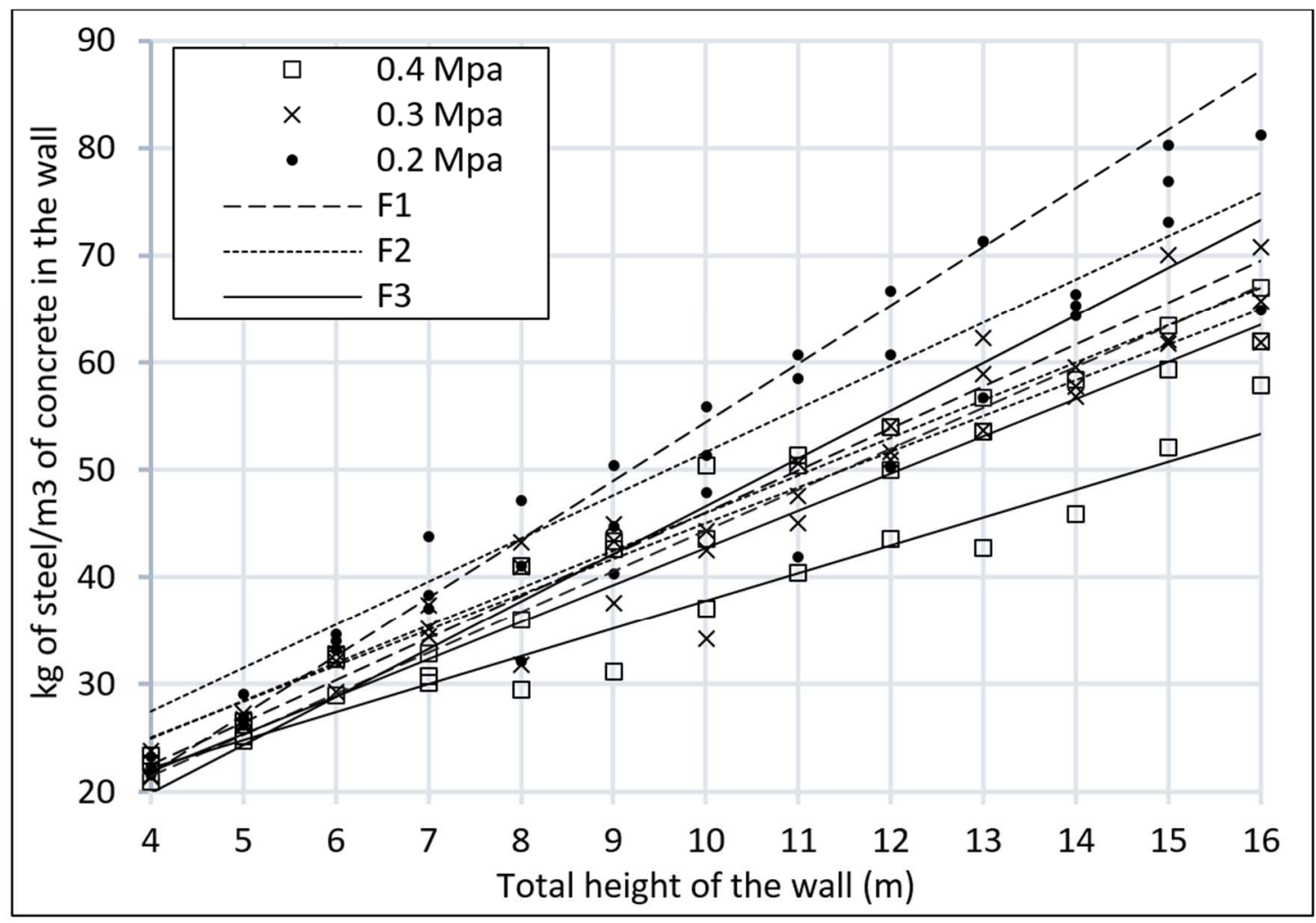

Fig. 16. Variation of ratio of the amount of steel per volume of concrete in the wall 


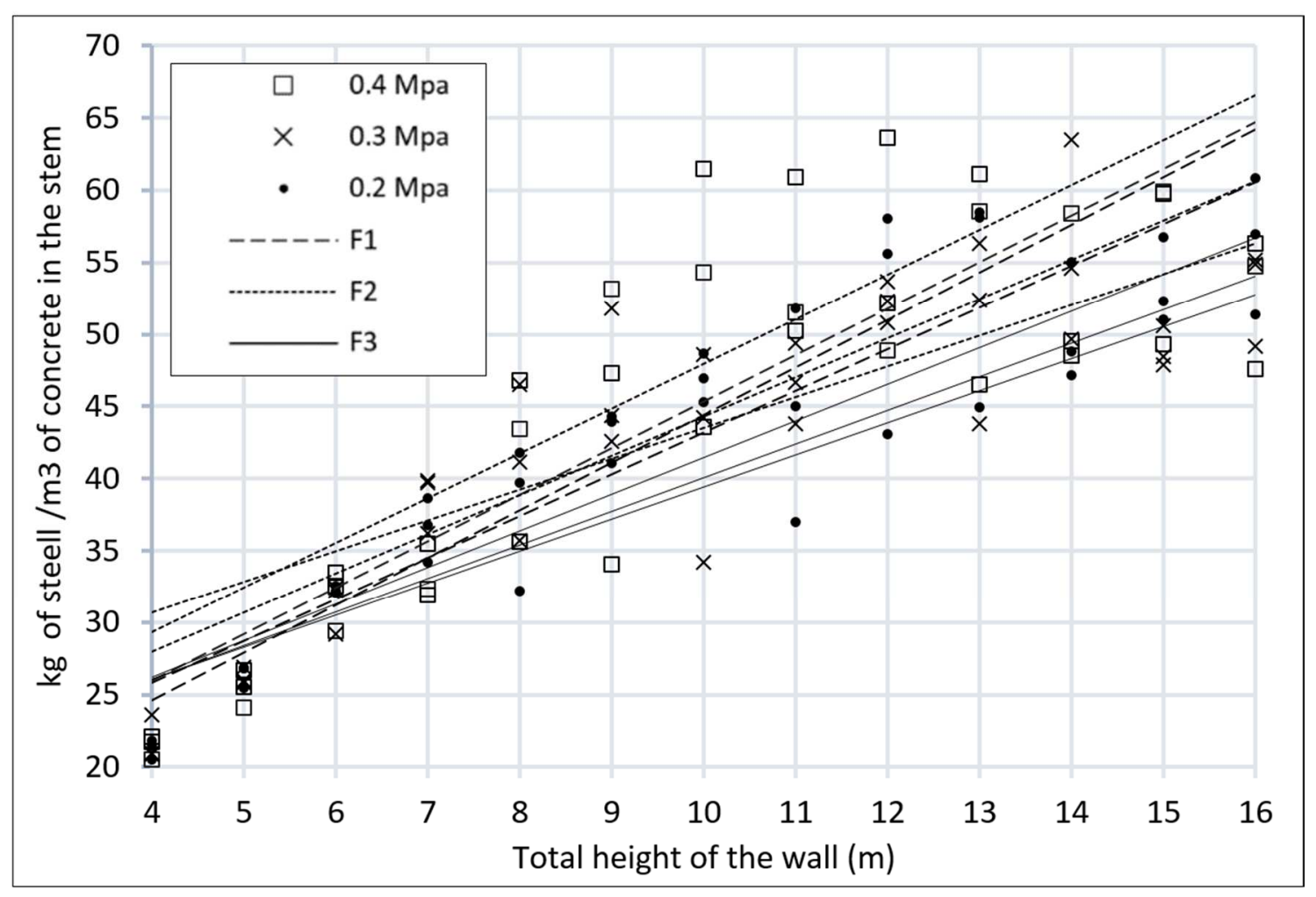

Fig. 17. Variation of ratio the amount of steel per volume of concrete in the stem

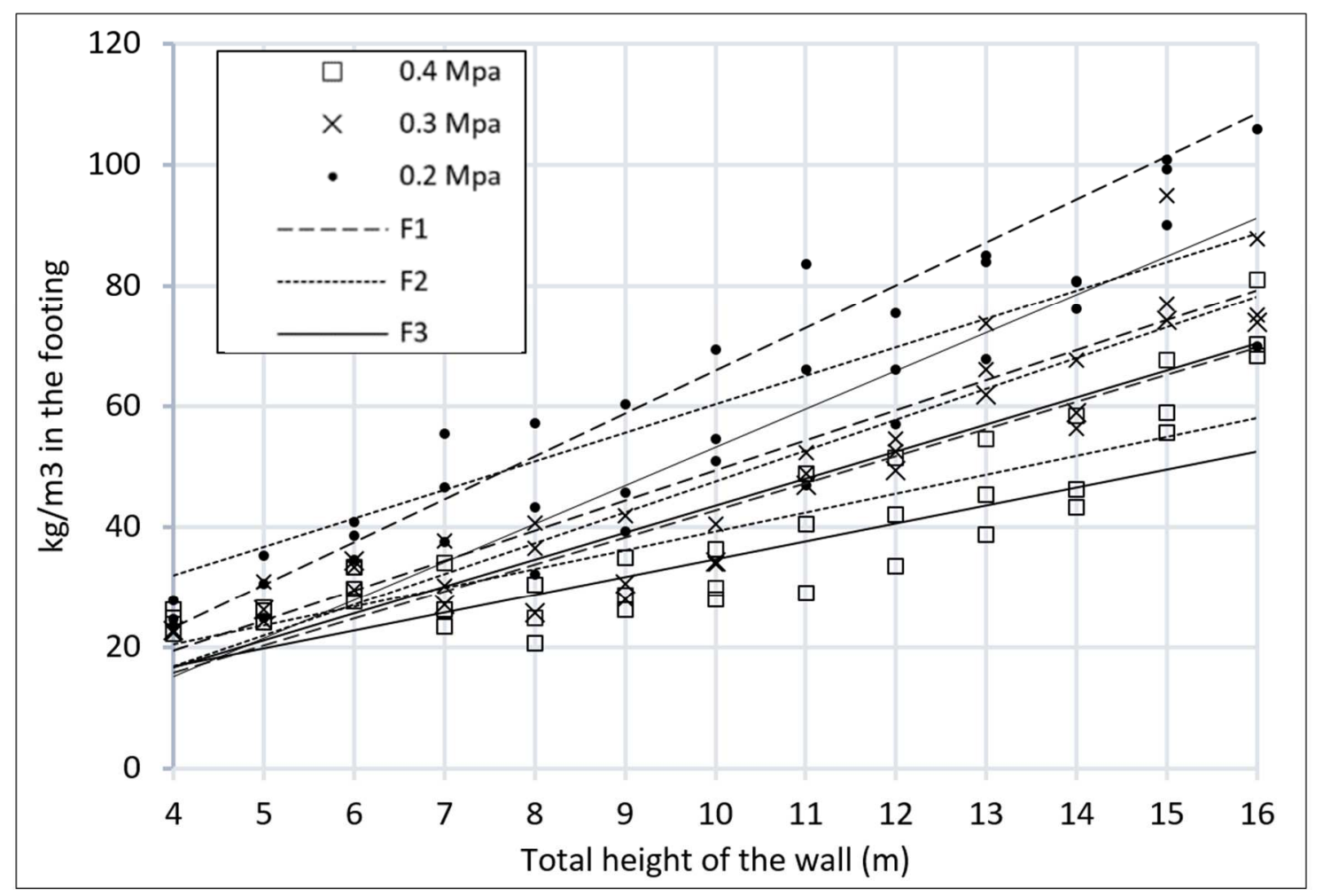

Fig.18. Variation of ratio the amount of steel per volume of concrete in the footing 